\title{
1 Delamination and recycling of Archaean crust caused by
}

\section{2 gravitational instabilities}

3

4 Tim E. Johnson", Michael Brown ${ }^{2}$, Boris Kaus ${ }^{1,3}$ \& Jill A. VanTongeren ${ }^{4}$

5

$6 \quad{ }^{1}$ Institute for Geoscience, University of Mainz, 55099 Mainz, Germany.

$7 \quad{ }^{2}$ Department of Geology, University of Maryland, College Park, MD 20742, USA.

$8 \quad{ }^{3}$ Department of Earth Sciences, University of Southern California, Los Angeles, CA 90089-

9 0740, USA.

${ }^{4}$ Department of Geology \& Geophysics, Yale University, New Haven, CT 06511, USA.

An extensive, thick MgO-rich primary crust underlain by highly residual mantle must have formed during the Archaean as a consequence of higher ambient mantle potential temperatures ${ }^{1}$. However, the preserved volume of this crust is low suggesting much of it was recycled $^{2}$. Further, the tonalite-trondhjemite-granodiorites that dominate exposed Archaean crust cannot have been generated directly from MgO-rich primary crust since a hydrated low-MgO basalt source is required ${ }^{3}$. Here we show that the thermodynamically stable mineral assemblages expected at the base of fully hydrated and anhydrous MgO-rich crust $45 \mathrm{~km}$ thick make it denser than the complementary underlying residual mantle. We use 2-D geodynamic models to explore the fate of this gravitationally unstable crust. Our results demonstrate that magmatically-overthickened MgO-rich crust, whether fully hydrated or anhydrous, could have delaminated by Rayleigh-Taylor instabilities for mantle potential temperatures $>1500-1550{ }^{\circ} \mathrm{C}$, depending on rheology. The dripping instabilities generate return flow of asthenospheric mantle that melts adiabatically producing additional primary crust. Melting of overthickened and dripping MgO-rich crust and intracrustal fractionation of primary magmas both may produce the hydrated 

associated ultramafic residues now must reside in the mantle.

Understanding the formation and reworking of Earth's early crust is important for models of mantle evolution. Earth's primary crust is a product of partial melting of the mantle. Most primary (oceanic) crust on modern Earth is produced at spreading ridges, is on average $6-7 \mathrm{~km}$ thick and is composed of mid-ocean ridge basalts (MORB; 5-8 wt\% MgO), the result of partial melting at melt fractions $(F)$ of $0.08-0.1$ and mantle potential temperatures $\left(T_{\mathrm{p}}\right)$ of $1280-1400$ ${ }^{\circ} \mathrm{C}^{4}$. This crust is recycled by subduction during which it is converted to eclogite. On the early Earth things were undoubtedly different. The occurrence of voluminous tonalite-trondhjemitegranodiorite (TTG) crust and komatiites, which are largely restricted to the Archaean ${ }^{5}$, and the volume of continental crust produced during the Archaean ${ }^{6}$ are consistent with a hotter Earth. Although the thermal evolution of Earth and the mechanism of heat loss remain matters of debate $^{7,8}$, higher $T_{\mathrm{p}}$ during the Archaean would have led to more extensive melting of the mantle and production of a thick (up to $45 \mathrm{~km}$ ) MgO-rich primary crust ${ }^{1,2}$. Komatiite magmatism associated with plumes and excess $T_{\mathrm{p}}$ may have contributed to the early crust, but the volume of komatiite in greenstone belts (0-20 vol.\%) suggests this played only a minor role ${ }^{9}$. Based on the petrology and geochemistry of volcanic rocks, the composition of model primary melts generated by varying degrees of partial melting of fertile peridotite can be calculated with reference to experiments ${ }^{4}$, from which the composition of the complementary residues are constrained by mass balance ${ }^{1,2}$. Near-pristine xenoliths of harzburgite that sample the Archaean lithospheric mantle are highly depleted in $\mathrm{FeO}, \mathrm{Al}_{2} \mathrm{O}_{3}$ and $\mathrm{CaO}$ relative to fertile mantle and have compositions that correspond well with modelled residua for melt fractions of $0.25-0.45^{2}$ and primary crust $25-45 \mathrm{~km}$ in thickness ${ }^{2}$. Samples of high $\mathrm{MgO}$ non-arc basalts from Archaean greenstone belts have compositions consistent with their derivation from primary

51 melts $^{1}$ (Fig. 1). However, the volume of these rocks in the exposed geologic record is low. 
Assuming these non-arc basalts are representative of primary crust ${ }^{1,2}$, then most of this crust is missing, which suggests it has been recycled or sequestered at depth in the mantle.

A plot of $\mathrm{MgO}$ content versus age for non-arc basalts ${ }^{1}$ shows that ambient $T_{\mathrm{p}}$ was $>1500$ ${ }^{\circ} \mathrm{C}$ during the Archaean, with a maximum in the Mesoarchaean (Fig. 1a). The inferred onset of secular cooling of the mantle broadly coincides with a marked decrease in the rate of crustal growth around $3 \mathrm{Ga}^{6}$, and may record the transition to dominantly subduction-driven plate tectonics on Earth ${ }^{10,11}$. Prior to this, most primary crust may have formed by intra- and overaccretion of melts above upwelling mantle driven by smaller wavelength convection ${ }^{11}$. With a higher basal heat flux and increased radiogenic heat production, temperatures close to the base of thick primary crust in the Archaean may have exceeded $1000{ }^{\circ} \mathrm{C}^{10}$, conditions under which partial melting of ultramafic rocks is likely if they were hydrated ${ }^{12,13}$.

The range in $T_{\mathrm{p}}$ for any given age suggested by the petrological data (Fig. 1a) is similar to temperature variations in mantle upwelling beneath modern mid-ocean ridges ${ }^{4}$, and would have given rise to variations in the composition and thickness of Archaean primary crust (Fig. 1c) and associated residual mantle. Such variations may have allowed different tectonic styles to operate in different parts of the ancient Earth ${ }^{11}$. Extreme ambient mantle temperatures $\left(T_{\mathrm{p}}>1600{ }^{\circ} \mathrm{C}\right)$ could have produced in situ primary crust $40-45 \mathrm{~km}^{\text {thick }}{ }^{2}$ (Fig. 1c). Subduction similar to that observed in contemporary plate tectonics may not have been possible under these conditions $^{8,11,14}$.

Here we test the postulate that thick primary crust produced in the early Archaean could have become gravitationally unstable with respect to the underlying mantle residues so that if locally thickened it became negatively buoyant and could have delaminated by Rayleigh-Taylor (RT) instabilities. To do this we model the equilibrium (minimum Gibbs free energy) mineral assemblages developed near the base of the crust for a wide range of metamorphosed (hydrated and anhydrous) primary crust compositions (Figs 2a,b and Supplementary Figs S1-S4) and their complementary (anhydrous) residues (Fig. 2c and Supplementary Figs S5 and S6) that account 
for secular changes in $T_{\mathrm{p}}, F$ and crustal thickness (see Methods). First, we calculate the stability of equilibrium mineral assemblages for a temperature of $1000{ }^{\circ} \mathrm{C}$ (Figs 2a,b and Supplementary Figs S1, S3), which corresponds to that expected near the base of 30-45 km thick crust based on the apparent thermal gradients recorded by Mesoarchaean to Neoarchaean metamorphic rocks ${ }^{10}$ and approximates the solidus temperature of hydrated ultramafic primary crust, inferred to lie between the fluid-absent solidi for amphibolite and amphibole-bearing MORB pyrolite and wehrlite $^{13,15}$. To assess the temperature sensitivity of the results, we also calculate phase equilibria at $900{ }^{\circ} \mathrm{C}$ (Fig. 2a and Supplementary Figs S2, S4). We use the results to calculate the density contrast at the crust-mantle interface for the range of compositions and temperatures modelled to assess the stability of the crust relative to the underlying residual mantle (Fig. 3). We incorporate the density data with a parameterized melting and melt extraction algorithm into a 2-D thermomechanical model (see Methods) to evaluate the dynamical plausibility of crustal recycling by RT instabilities for end-member simulations involving either hydrated or anhydrous crust (Supplementary information, 3 Geodynamic numerical modelling), wet or dry mantle, and various crustal thicknesses, $T_{\mathrm{p}}$ and Moho temperatures (Fig. 4 and Supplementary Figs S8-S12). By integrating results from both thermodynamic and 2-D numerical modelling, we draw several important inferences about Archaean tectonics, partial melting of delaminated primary crust, intracrustal differentiation and the generation of TTG magmas.

The variation in density between fully hydrated and anhydrous crust is shown in Figs 3a and $b$, the density of the complementary residual mantle in Fig. 3c, and the effect on the potential instability of the crust in Fig. 3d. Thick anhydrous crust and hydrated primary crust with high $\mathrm{MgO}(>21-22 \mathrm{wt} \%)$, generated at extreme $T_{\mathrm{p}}\left(>1600^{\circ} \mathrm{C}\right)$, would have been gravitationally unstable at its base (Fig. 3d). Primary melts with lower $\mathrm{MgO}\left(<\right.$ or $\left.<<21 \mathrm{wt} \% ; T_{\mathrm{p}}<1600{ }^{\circ} \mathrm{C}\right)$ would have produced lower crustal thicknesses (Fig. 1c) and overthickening would be required for the base to become gravitationally unstable (Fig. 3d). 
104 experiment for the evolution of primary crust during the early Archaean (Fig. 4). Thick MgO-

105 rich primary crust forms above hot upwelling mantle by near-isentropic melting. Local

106 thickening causes material at the base of the crust to become gravitationally unstable. Using 2-D

107 thermomechanical modelling we are able to show that delamination of this over-thickened

108 primary crust occurs by RT instabilities once the viscosity is sufficiently low (Fig. 4) and occurs

109 for a range of crustal thicknesses and geotherms (see Methods and Supplementary information, 3

110 Geodynamic numerical modelling). A scaling analysis reveals that the two requirements for the

111 instabilities to occur are a sufficiently thick negatively buoyant lower crust and low effective

112 viscosities of the uppermost mantle and lower crust (see Supplementary information 3.2.3). For

113 realistic rheologies this mechanism starts to operate at $T_{p} 1500-1550{ }^{\circ} \mathrm{C}$ but is particularly

114 effective at $T_{p} \geq 1600{ }^{\circ} \mathrm{C}$, consistent with predicted upper mantle temperatures in the Archaean

115 (Fig. 1). Sinking primary crust could have partially melted directly to produce basalt ${ }^{16}$ and/or

116 reacted with and refertilised the underlying residual mantle to induce further melting ${ }^{16,17}$. Mantle

117 return flow would have caused additional adiabatic melting and further crustal thickening (Fig. 4

118 and Supplementary information, 3 Geodynamic numerical modelling). At the predicted

119 temperatures, partial melting near the base of overthickened hydrated primary crust would result

120 in intracrustal differentiation. These secondary magmas would have had lower $\mathrm{MgO}$ contents

121 than the primary crust.

122 The depths at which the base of the primary crust becomes gravitationally unstable

123 represent maxima. Firstly, the modelled crust is taken to be homogeneous. However, similar to

124 present-day primary crust (intra-oceanic arc crust ${ }^{18}$, oceanic plateaux ${ }^{19,20}$ and oceanic crust ${ }^{21}$ ),

125 primary crust in the Archaean is likely to have differentiated into lower $\mathrm{MgO}$ and higher $\mathrm{MgO}$

126 (cumulate-rich) portions ${ }^{19}$. Secondly, the modelled residua (Fig. 2c) are the average

127 compositions of the melt-depleted mantle and do not account for the decrease in the degree of 
128 partial melting with depth. Consequently, the residual mantle immediately underlying the crust

129 would have been more depleted, and marginally less dense, than modelled.

130 We emphasise that high $\mathrm{MgO}(>$ or $>>18 \mathrm{wt} \% \mathrm{MgO})$ primary crust produced during the

131 Archaean would have been ultramafic not basaltic ${ }^{14}$. Compositions in the lower portion of over-

132 thickened primary crust would have been silica-undersaturated metapyroxenite or

133 metahornblendite, additionally containing garnet at higher pressures $(>1.0-1.5 \mathrm{GPa})$ or at lower

134 degrees of hydration (Figs 2a,b and Supplementary Figs S1 and S3). High MgO garnet

135 metapyroxenite (16-23 wt $\% \mathrm{MgO})$ xenoliths of Archaean age have mantle-like oxygen isotopic

136 compositions $^{22-24}$ and generally record high equilibrium temperatures ${ }^{22}$. They are

137 compositionally and mineralogically similar to modelled high $\mathrm{MgO}$ compositions ${ }^{22}$ and may

138 represent near pristine primary crust that foundered into the depleted mantle ${ }^{24}$. By contrast, low

$139 \mathrm{MgO}$ eclogite xenoliths have omphacitic clinopyroxene, highly variable oxygen isotopic

140 compositions and may contain accessory kyanite, quartz/coesite, K-feldspar and/or corundum ${ }^{23}$.

141 They likely represent highly fractionated crustal compositions with a multi-stage evolutionary

142 history $^{22}$.

143 The high $\mathrm{SiO}_{2}, \mathrm{Na} / \mathrm{K}, \mathrm{Sr} / \mathrm{Y}$ and depleted HREE contents of sodic Archaean TTGs suggest

144 that most were derived by partial melting of garnet amphibolite ${ }^{3,25}$. At $1000{ }^{\circ} \mathrm{C}$ garnet

145 amphibolite is stable only in hydrated primary crust with $\mathrm{MgO}<$ or $<<18 \mathrm{wt} \%$ at $P>1.0 \mathrm{GPa}$

146 (Fig. 2a, Figs S1), and this stability is further reduced at $900{ }^{\circ} \mathrm{C}$ (Fig. 2a, Figs S3). Thus, TTG

147 melts cannot have been generated from partial melting of unmodified Archaean high-MgO

148 primary crust, which would result in basaltic or nephelinitic melt compositions ${ }^{14}$, but were

149 derived from crust of basaltic composition ${ }^{3}$. This basaltic crust could have been produced by

150 differentiation of primary melts by crystal fractionation ${ }^{14}$ or by partial melting of over-thickened

151 primary crust. Thus, a two-stage process is required for the production of Archaean TTG

152 magmas. 
constrained, primary crustal compositions indicating $T_{\mathrm{p}}>1600{ }^{\circ} \mathrm{C}$ appear to be limited to occurrences between c $3.5 \mathrm{Ga}$ (or earlier) and c $1.9 \mathrm{Ga}$ (Fig. 1a). This interval spans the onset of production of ultra-thick primary crust and tectonics dominated by RT instabilities to the transition to a dominantly modern-style of subduction, and may define an early tectonic regime with globally variable tectonic styles controlled by the spatial range in $T_{\mathrm{p}}$ at any point in time ${ }^{11}$. Rather than subduction-driven plate tectonics, delamination by RT instabilities of overthickened primary crust was responsible for the production and stabilization of the bulk of the continental crust.

\section{Methods}

164 The phase equilibria are presented as isothermal pressure $(P)$ - composition $(X)$ pseudosections calculated in the chemical systems $\mathrm{Na}_{2} \mathrm{O}-\mathrm{CaO}-\mathrm{FeO}-\mathrm{MgO}-\mathrm{Al}_{2} \mathrm{O}_{3}-\mathrm{SiO}_{2}-\mathrm{H}_{2} \mathrm{O}-\mathrm{TiO}_{2}-\mathrm{O}_{2}$ (NCFMASHTO) for the primary melt compositions (Supplementary Figs S1, S3, S7 and S9) and $\mathrm{CaO}-\mathrm{FeO}-\mathrm{MgO}-\mathrm{Al}_{2} \mathrm{O}_{3}-\mathrm{SiO}_{2}-\mathrm{O}_{2}$ (CFMASO) for the complementary residue compositions (Supplementary Fig. S5 and S11) using Perple- $\mathrm{X}^{26}$ with internally consistent thermodynamic data for end members ${ }^{27}$ and the most recently calibrated activity-composition models for solidsolution phases ${ }^{28}$ (see Supplementary information, 2 Phase equilibria modelling). The modelled compositional range for primary crust is a binary mixture between the primary melt composition for $\operatorname{MORB}(X=0)$ and a fictive end member composition $(\mathrm{MgO}$ of $25 \mathrm{wt} \% ; X=1)$ as a proxy

173 for primary crust generated at extreme $T_{\mathrm{p}}$ (Fig. 1). The composition (in mol.\%) of these end

174 members in terms of the components $\mathrm{SiO}_{2}, \mathrm{TiO}_{2}, \mathrm{Al}_{2} \mathrm{O}_{3}, \mathrm{FeO}, \mathrm{MgO}, \mathrm{CaO}, \mathrm{Na}_{2} \mathrm{O}, \mathrm{O}_{2}$ is: 49.49, $1750.66,10.11,6.69,17.72,12.72,2.28,0.33(X=0)$ and 42.96, 0.60, 2.61, 10.09, 34.97, 7.53, 0.99, $0.25(X=1)$. The end member compositions of the binary bulk compositional range for the

177 complementary residue in terms of the components $\mathrm{SiO}_{2}, \mathrm{Al}_{2} \mathrm{O}_{3}, \mathrm{FeO}, \mathrm{MgO}, \mathrm{CaO}, \mathrm{O}_{2}$ is: 38.25 , 
179 calculations use an $\mathrm{Fe}^{3+} /\left(\mathrm{Fe}^{3+}+\mathrm{Fe}^{2+}\right)$ ratio of 0.1 (see Supplementary information, 2 Phase

180 equilibria modelling). The phase equilibria modelling considers the phases olivine (ol), garnet

181 (g), clinopyroxene (cpx), orthpyroxene (opx), hornblende (hb), plagioclase (pl), quartz (q),

182 ilmenite (ilm), rutile (ru), spinel (sp), magnetite (mt), hematite (hem) and $\mathrm{H}_{2} \mathrm{O}$. Based on the

183 phase equilibria, densities are calculated for hydrated primary crust, anhydrous primary crust and

184 the complementary residues to determine the relative densities of hydrated or anhydrous crust

185 compared to the underlying residual mantle at 1000 and $900{ }^{\circ} \mathrm{C}$.

186 The parameterized 2-D thermomechanical models solve the governing conservation

187 equations of mass, momentum and energy of slowly creeping fluids on geological timescales

188 using the finite element code MILAMIN_VEP ${ }^{29,30}$. The code employs realistic rock densities

189 that have been computed as a function of $P$ and $T$ for the given rock types described above, as

190 well as laboratory-constrained creep laws. In addition, we have implemented partial melting of

191 mantle lithosphere and underlying fertile mantle, and added a simplified melt extraction

192 algorithm which removes melt from the mantle as soon as $>5 \%$ melt is present and emplaces it

193 on top of the crust. We have performed systematic studies to understand the sensitivity of the

194 results to input parameters, and developed a scaling analysis that demonstrates that the

195 underlying physics of the models is governed by density-driven instabilities that erode the base

196 of the crust in relatively small pulses once the viscosity of the mantle lithosphere underneath the

197 crust is sufficiently low (see Supplementary information, 3 Geodynamic numerical modelling).

\section{References}

200 1. Herzberg, C., Condie, K. \& Korenaga, J. Thermal history of the Earth and its petrological

$201 \quad$ expression. Earth Planet. Sci. Lett. 292, 79-88 (2010).

202 2. Herzberg, C. \& Rudnick, R. Formation of cratonic lithosphere: An integrated thermal and 203 petrological model. Lithos 149, 4-15 (2012). 
3. Foley, S., Tiepolo, M. \& Vannucci, R. Growth of early continental crust controlled by melting of amphibolite in subduction zones. Nature 417, 837-840 (2002).

4. Herzberg, C., Asimow, P. D., Arndt, N., Niu, Y., Lesher, C. M., Fitton, J. G., Cheadle, M. J. \& Saunders, A. D. Temperatures in ambient mantle and plumes: constraints from basalts, picrites and komatiites. Geochemistry, Geophysics, Geosystems 8 (2007).

5. Goodwin, A. Precambrian Geology: the Dynamic Evolution of the Continental Crust (Academic Press, 1991).

6. Dhuime, B., Hawkesworth, C. J., Cawood, P. A. \& Storey, C. D. A change in the geodynamics of continental growth 3 billion years ago. Science 335, 1334-1336 (2012).

7. Davies, G. F. Effect of plate bending on the Urey ratio and the thermal evolution of the mantle. Earth Planet. Sci. Lett. 287, 513-518 (2009).

8. van Hunen, J. \& Moyen, J.-F. Archean subduction: Fact or fiction? Annu. Rev. Earth Planet. Sci. 40, 195-219 (2012).

9. Arndt, N. T. \& Lesher, C. M. Komatiites, in Selley, R. C., Cocks, L. R. M. \& Plimer, I. R. (eds) Encyclopedia of Geol. Vol. 3, 260-267 (Elsevier, New York, 2005).

10. Brown, M. Metamorphic conditions in orogenic belts: A record of secular change. Int. Geol. Rev. 49, 193-234 (2007).

11. Sizova, E., Gerya, T., Brown, M. \& Perchuk, L. Subduction styles in the Precambrian: Insight from numerical experiments. Lithos 116, 209-229 (2010).

12. Mareschal, J.-C. \& Jaupart, C. Archean thermal regime and stabilization of the cratons. In Geophys. Monogr. Ser. 164, 61-73 (AGU, Washington, DC, 2006).

13. Niida, K. \& Green, D. H. Stability and chemical composition of pargasitic amphibole in MORB pyrolite under upper mantle conditions. Contrib. Mineral. Petrol. 135, 18-40 (1999). shallow subduction. Nature 421, 249-252 (2003). 
15. Rushmer, T. Partial melting of two amphibolites: contrasting experimental results under fluid-absent conditions. Contrib. Mineral. Petrol. 107, 41-59 (1991).

16. Elkins-Tanton, L. T. Continental magmatism, volatile recycling, and a heterogeneous mantle caused by lithospheric gravitational instabilities. J. Geophys. Res. 112, B03405 (2007).

17. Bedard, J. H. A catalytic delamination-driven model for coupled genesis of Archaean crust and sub-continental lithospheric mantle. Geochim. Cosmochim. Acta 70, 1188-1214 (2006).

18. Jagoutz, O., Müntener, O., Schmidt, M. W. \& Burg, J.-P. The roles of flux- and decompression melting and their respective fractionation lines for continental crust formation: Evidence from the Kohistan arc. Earth Planet. Sci. Lett. 303, 25-36 (2011).

19. Kerr, A. C., Tarney, J., Nivia, A., Marriner, G. F. \& Saunders, A. D. The internal structure of oceanic plateaus: inferences from obducted Cretaceous terranes in western Colombia and the Caribbean. Tectonophysics 292, 173-188 (1998).

20. Fitton, J. G., Mahoney, J. J., Wallace, P. J. \& Saunders, A. D. (eds) Origin and evolution of the Ontong Java Plateau. Geol. Soc. Spec. Publ. 229, 1-368 (2004).

21. Kelemen, P. B., Koga, K. \& Shimizu, N. Geochemistry of gabbro sills in the crust-mantle transition zone of the Oman ophiolite: implications for the origin of the oceanic lower crust. Earth Planet. Sci. Lett. 146, 475-488 (1997).

22. Gonzaga, R. et al. Eclogites and garnet pyroxenites: Similarities and differences. J. Volcanol. Geotherm. Res. 190, 235-247 (2010).

23. Jacob, D. Nature and origin of eclogite xenoliths from kimberlites. Lithos 77, 295-316 (2004).

24. Barth, M. G. et al. Geochemistry of xenolithic eclogites from West Africa, part 2: origins of the high MgO eclogites. Geochim. Cosmochim. Acta 66, 4325-4345 (2002).

25. Moyen, J.-F. The composite Archaean grey gneisses: Petrological significance, and evidence for a non-unique tectonic setting for Archaean crustal growth. Lithos 123, 21-36 (2011). 
26. Connolly, J. A. D. Computation of phase equilibria by linear programming: a tool for geodynamic modeling and its application to subduction zone decarbonation. Earth Planet. Sci. Lett. 236, 524-541 (2005).

27. Holland T. J. B. \& Powell R. An internally consistent thermodynamic data set for phases of petrological interest. J. Metamorph. Geol. 16, 309-43 (1998).

28. Diener, J. F. A. \& Powell, R. Revised activity-composition relations for clinopyroxene and amphibole. J. Metamorph. Geol. 30, 131-142 (2012).

29. Thielmann, M. \& Kaus, B. Shear heating induced lithospheric-scale localization: Does it result in subduction? Earth Planet. Sci. Lett. 359-360, 1-13 (2012).

30. Kaus, B. Factors that control the angle of shear bands in geodynamic numerical models of brittle deformation. Tectonophys. 484, 36-47 (2010).

\section{Acknowledgements}

We thank S. Aulbach, J. Connolly, G. Davies, S. Fischer, S.F. Foley, E.C.R. Green, C. Herzberg, D.E. Jacob \& R.W. White for comments. M.B. \& T.E.J. acknowledge financial support from the Geocycles Earth Systems Research Centre, University of Mainz. B.K. was financed by ERC Starting Grant 258830.

\section{Author Contributions}

M.B. and T.E.J. developed the project; T.E.J. calculated the phase diagrams and B.K. developed and ran the numerical models. All authors discussed the results and were involved in writing the paper.

\section{Additional information}


Supplementary Information is available in the online version of the paper. Reprints and

279 permissions information is available online at www.nature.com/reprints. Correspondence and 280 requests for materials should be addressed to T.E.J.

281

\section{Competing financial interests}

283 The authors declare no competing financial interests.

\section{Figure legends}

Figure 1 | Calculated primary melt compositions for Precambrian non-arc basalts. a, $\mathrm{MgO}$

(mantle potential temperature) vs age (see Supplementary information, supplementary notes for

Fig. 1a); ambient mantle potential temperature peaked during the Archaean. b, $\mathrm{MgO}$ (mantle potential temperature) vs $\mathrm{FeO}$; the primary melt compositions for $\mathrm{MORB}(X=0)$ and a fictive composition with $25 \mathrm{wt} \% \mathrm{MgO}(X=1)$ define end-members of the binary compositional range used in the thermodynamic modelling. c, $\mathrm{MgO}$ (mantle potential temperature) vs melt fraction $(F)$ based on the relationship $F=1.456-2.189(\mathrm{FeO} / \mathrm{MgO}) ; \sim 1 \mathrm{~km}$ of crust is produced per 1 vol. $\%$ melting ${ }^{2}$.

Figure 2 | Results of thermodynamic modelling of primary crust and complementary residues at $1000{ }^{\circ} \mathrm{C}$. Metamorphic mineral assemblage stability fields for hydrated a, and anhydrous b, primary crust, and c, complementary residues (based on Supplementary Figs S1-

S6; in a, note reduced stability field for amphibolite at $900^{\circ} \mathrm{C}$ ); line shows approximate thickness of primary crust in relation to $\mathrm{MgO}$ content. Primary melt compositions for Precambrian non-arc basalts and inferred mantle potential temperatures $\left(T_{\mathrm{p}}\right)$ are shown along the abscissa. Extrapolated pressures at $1000{ }^{\circ} \mathrm{C}$ (right-hand ordinate) are based on apparent thermal

303 gradients recorded by metamorphosed Precambrian rocks ${ }^{10}$. 
305 Figure 3 | Density of primary crust and complementary residues. Densities calculated at

$3061000{ }^{\circ} \mathrm{C}$ plotted against $\mathrm{MgO}$ content for $\mathbf{a}$, hydrated primary crust, $\mathbf{b}$, anhydrous primary crust

307 and $\mathbf{c}$, the complementary residues. d, Shows the relative density of hydrated crust compared to

308 the underlying residual mantle at $1000^{\circ} \mathrm{C}$ against $\mathrm{MgO}$ of the primary crust with the equality

309 line for anhydrous crust at $1000^{\circ} \mathrm{C}$ and those for $900{ }^{\circ} \mathrm{C}$ (based on Supplementary Fig. S7)

310 superimposed. The solid (hydrated) and dashed (anhydrous) lines separate stable primary crust

311 (below) from potentially unstable primary crust (above).

312

313 Figure 4 | Results of geodynamic modelling: snapshots from an experiment with $45 \mathrm{~km}$

314 thick initial primary crust and $\boldsymbol{T}_{\boldsymbol{p}}$ of $1600{ }^{\circ} \mathrm{C}$. a, Model configuration and initial conditions

315 (dark blue, initial primary crust; light blue, negatively buoyant initial primary crust; dark pink-

316 brown, lithospheric mantle; light pink-brown, unmelted asthenosphere; yellow, melt-bearing

317 asthenosphere). $\mathbf{b}$, Shows local thickening of the initial primary crust by addition of new primary

318 crust (green) and delamination of negatively buoyant initial primary crust. Large-scale mantle

319 flow is caused mainly by the positive buoyancy of the melt-bearing asthenosphere; crustal drips

320 induce smaller circulation patterns. c, Shows density (left) and viscosity (right) for the left-hand

321 and right-hand halves of $b$, respectively. $\mathbf{d}$, Shows local thickening and delamination of

322 negatively buoyant new primary crust. 

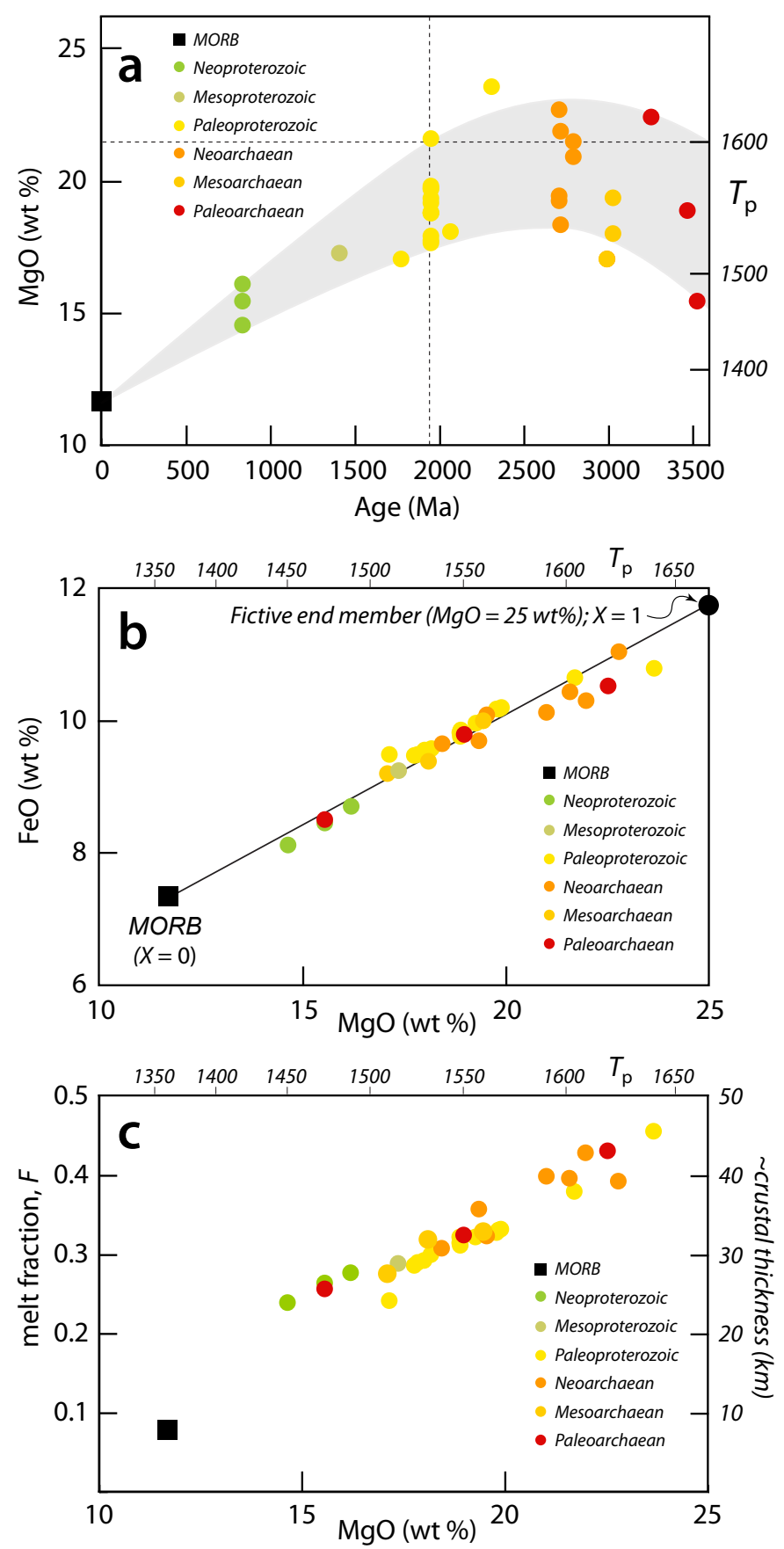

Figure 1 

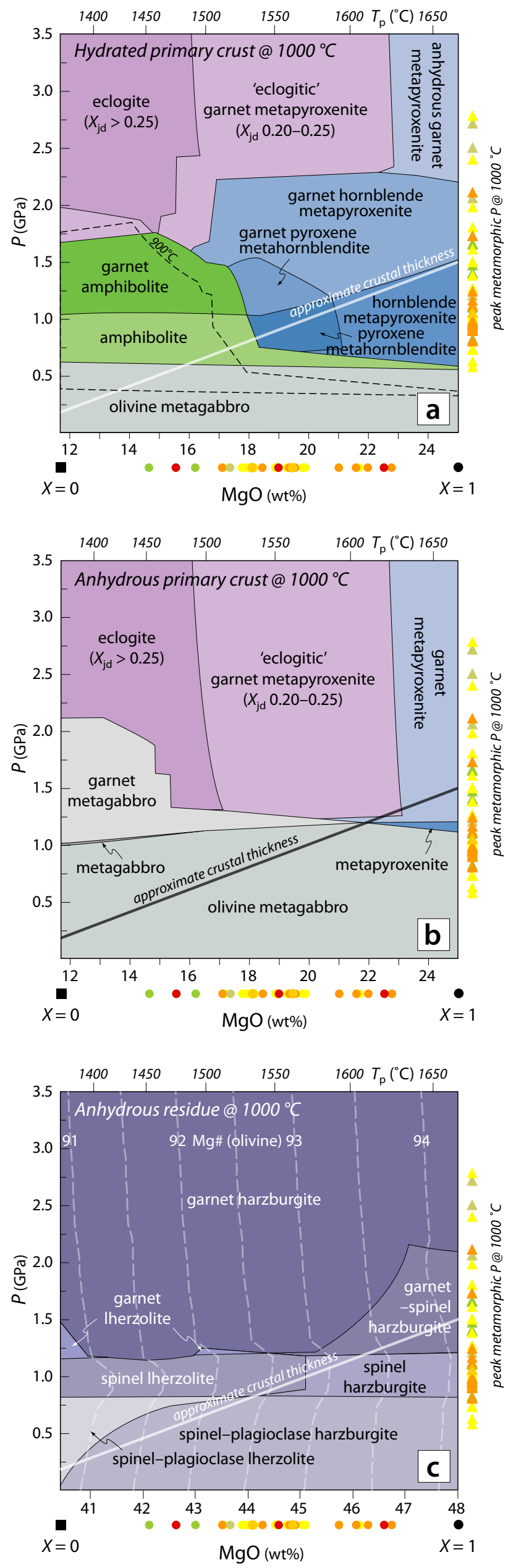

Figure 2 

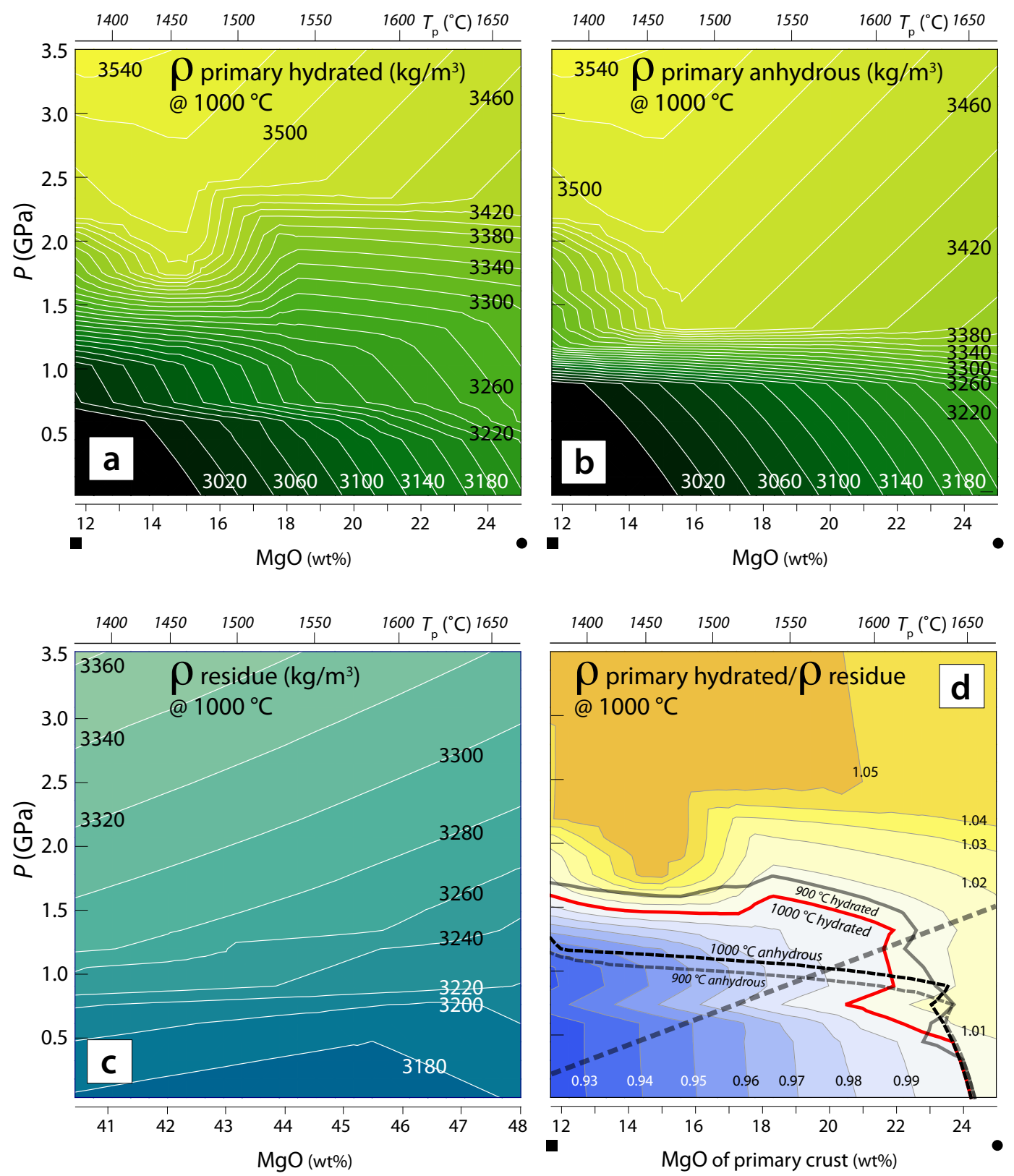

Figure 3 

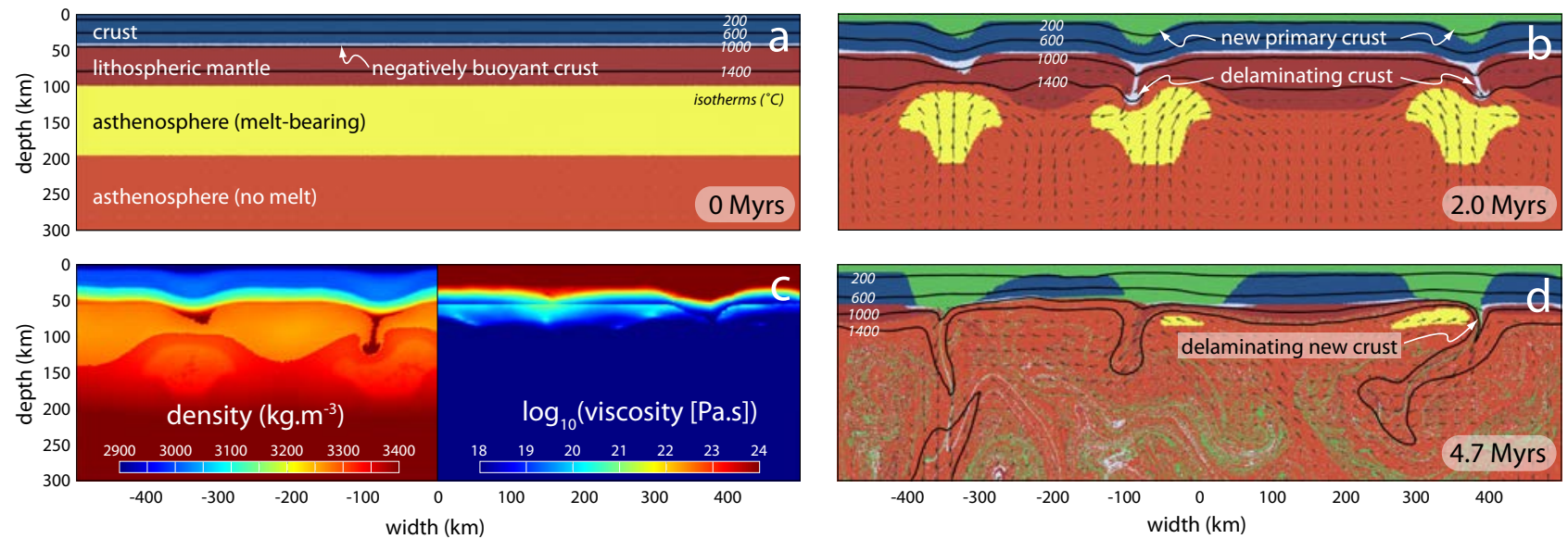

Figure 4 


\title{
Delamination and recycling of Archaean crust caused by
}

\section{gravitational instabilities}

\author{
Tim E. Johnson ${ }^{1}$, Michael Brown ${ }^{2}$, Boris Kaus ${ }^{1,3}$ \& Jill A. VanTongeren ${ }^{4}$ \\ ${ }^{1}$ Institute for Geoscience, University of Mainz, 55099 Mainz, Germany. \\ ${ }^{2}$ Department of Geology, University of Maryland, College Park, MD 20742, USA. \\ ${ }^{3}$ Department of Earth Sciences, University of Southern California, Los Angeles, CA 90089-0740, USA. \\ ${ }^{4}$ Department of Geology \& Geophysics, Yale University, New Haven, CT 06511, USA.
}

Contents:

1. Supplementary notes for Fig. 1a

2. Phase equilibria modelling

3. Geodynamic numerical modelling

4. References

\section{Supplementary notes for Fig. 1a}

The data used in Fig. 1a are taken from Herzberg et al. (2010) with the following corrections to the ages: Coonterunah Group, Pilbara craton, 3.515 Ga (Green et al., 2000, p. 71); Sulfur Springs Group, Pilbara craton, $3.245 \mathrm{Ga}$ (mean of maximum and minimum age constraints in Smithies et al., 2005, Fig. 2); Warrawoona Group Pilbara craton, 3.459 Ga (mean of maximum and minimum age constraints in Kato \& Nakamura, 2003, p. 193); Ivisaartoq, Greenland, $3.018 \mathrm{Ga}$ (mean of maximum and minimum age constraints in Polat et al., 2008, p. 297); Iringora structure, north Karelian greenstone belt, Finland, 2.282 Ga (Shchipansky et al., 2004, p.448); Kushtagi-Hungund greenstone belt, India, $2.707 \mathrm{Ga}$ (Balakrishnan et al., 1999, p. 74); Phulad ophiolite, Delhi Supergroup, Rajasthan, India, 1.4 Ga (minimum age, Volpe \& Macdougall, 1990, p. 186); Yiyang, South China Block, 0.823 Ga (Wang et al., 2007, p. 1104); Chukotat Group, Cape Smith belt, Canada (mean of maximum and minimum age constraints in St. Onge et al., 1999, Fig. 3); Nathdwara, Aravalli Supergroup, India, 2.3 Ga (Ahmad et al., 2008, p. 155); Vermillion greenstone belt, Minnesota, USA, 2.7 Ga (Card, 1990).

\section{Phase equilibria modelling}

The phase equilibria modelling uses primary melt compositions calculated by inversion of the major element chemistry of non-arc basalts of varying age as a proxy for the changing composition of the primary crust and by mass balance its complementary residue with time 
(Herzberg et al., 2010). The results are presented as isothermal (temperature $=1000$ or $900{ }^{\circ} \mathrm{C}$ ) pressure $(P)$ - composition $(X)$ pseudosections calculated in the $\mathrm{Na}_{2} \mathrm{O}-\mathrm{CaO}-\mathrm{K}_{2} \mathrm{O}-$ $\mathrm{FeO}-\mathrm{MgO}-\mathrm{Al}_{2} \mathrm{O}_{3}-\mathrm{SiO}_{2}-\mathrm{H}_{2} \mathrm{O}-\mathrm{TiO}_{2}-\mathrm{O}_{2}$ (NCKFMASHTO) chemical system for the primary melt compositions and the $\mathrm{CaO}-\mathrm{FeO}-\mathrm{MgO}-\mathrm{Al}_{2} \mathrm{O}_{3}-\mathrm{SiO}_{2}-\mathrm{O}_{2}$ (CFMASO) chemical system for the complementary residue compositions. Calculation were performed using Perple_X (Connolly, 2005) and the internally consistent thermodynamic dataset of Holland \& Powell (1998) with the following activity-composition models for solid-solution phases: garnet (White et al. 2007), clinopyroxene and amphibole (Diener \& Powell, 2012), orthopyroxene and spinel-magnetite (White et al., 2002), plagioclase (Holland \& Powell, 2003), and ilmenite-hematite (White et al., 2000). FMS olivine incorporates a symmetric Fe- $\mathrm{Mg}$ interaction parameter $\left(W_{\mathrm{fo}, \mathrm{fa}}\right)$ of $8 \mathrm{~kJ}$.

The primary crust is modelled either as fully hydrated, requiring $<$ or $<<1.5 \mathrm{wt} \% \mathrm{H}_{2} \mathrm{O}$, in which $\mathrm{H}_{2} \mathrm{O}$ is contained within hornblende with $\sim 2 \mathrm{wt} \% \mathrm{H}_{2} \mathrm{O}$, or as anhydrous, whereas the residues are modelled as anhydrous. The hydrated and anhydrous end-member cases allow consideration of variable hydration of the primary crust. The modelled compositional range for primary crust is a binary mixture between the primary melt composition for MORB $(X=0)$ and a fictive end member composition $(\mathrm{MgO}$ of $25 \mathrm{wt} \% ; X=1)$ as a proxy for primary crust generated at extreme $T_{\mathrm{p}}$ (Herzberg et al., 2010; Fig. 1b). The composition of these end members in terms of the components $\mathrm{SiO}_{2}, \mathrm{TiO}_{2}, \mathrm{Al}_{2} \mathrm{O}_{3}, \mathrm{FeO}, \mathrm{MgO}, \mathrm{CaO}, \mathrm{Na}_{2} \mathrm{O}$, $\mathrm{O}_{2}$ expressed as mol.\% and normalised to $100 \%$ is: $49.49,0.66,10.11,6.69,17.72,12.72$, $2.28,0.33(X=0)$ and 42.96, 0.60, 2.61, 10.09, 34.97, 7.53, 0.99, $0.25(X=1)$. The end member compositions of the binary compositional range for the complementary residue in terms of the components $\mathrm{SiO}_{2}, \mathrm{Al}_{2} \mathrm{O}_{3}, \mathrm{FeO}, \mathrm{MgO}, \mathrm{CaO}, \mathrm{O}_{2}$ expressed as mol.\% and normalised to $100 \%$ is: $38.25,1.61,5.80,51.66,2.53,0.15(X=0)$ and $35.76,1.28,4.07$, $58.52,0.27,0.10(X=1)$. All calculations use a constant $\mathrm{Fe}^{3+} /\left(\mathrm{Fe}^{3+}+\mathrm{Fe}^{2+}\right)$ ratio of 0.1 (Berry et al., 2008). The model calculation and phase diagrams include the following phases (and abbreviations): olivine (ol), garnet (g), clinopyroxene (cpx), orthopyroxene (opx), hornblende $(\mathrm{hb})$, plagioclase (pl), quartz (q), ilmenite (ilm), rutile (ru), spinel (sp), magnetite (mt), hematite (hem) and $\mathrm{H}_{2} \mathrm{O}$ as appropriate.

Figure 2 shows the hydrated (Fig. 2a) and anhydrous (Fig. 2b) metamorphic mineral assemblage stability fields for the range of primary melt compositions (from $X=0$ to $X=1$ ) and their complementary residues, Fig. $2 \mathrm{c}$, for pressure up to $3.5 \mathrm{GPa}$ at $1000{ }^{\circ} \mathrm{C}$; also shown in Fig. 2a is the reduced stability field of amphibolite at $900^{\circ} \mathrm{C}$. These simplified diagrams are based on the complete phase diagrams shown in Figs S1a-S6a and the rock names used in Fig. 2 are based on the modes shown in Figs S1b-S6b, which are located at the end of this section. In Figs 2a, b, the green field of amphibolite and garnet amphibolite is defined by assemblages containing both hornblende and plagioclase. Ultramafic rocks shown in blue are defined by assemblages lacking plagioclase but containing diopsidic clinopyroxene $(X \mathrm{jd}$ $<0.20$ ), within which metahornblendites contain $>50$ vol. $\%$ hornblende. In the purple eclogite field garnet and omphacitic clinopyroxene $(X j \mathrm{~d}>0.25)$ coexist with rutile and quartz/coesite. 'Eclogitic' rocks in pale purple are modally dominated by garnet and clinopyroxene of 'intermediate' composition $(0.20<X \mathrm{jd}<0.25)$. For primary crust at $1000{ }^{\circ} \mathrm{C}$, clinopyroxene abundance varies widely from $<15$ to $>50$ vol. $\%$, but is predicted in all assemblages; it is diopside except at high $P(>1.8 \mathrm{GPa})$ and low $\mathrm{MgO}(<15 \mathrm{wt} \%)$, where it is omphacite. Hornblende contents are up to $60 \mathrm{vol} . \%$, with maximum abundances at around $1.0 \mathrm{GPa}$ and $18 \mathrm{wt} \% \mathrm{MgO}$. Garnet is stable above $1.0 \mathrm{GPa}$ at low $\mathrm{MgO}$ and above $1.5 \mathrm{GPa}$ at the highest $\mathrm{MgO}$ contents modelled. Low $\mathrm{MgO}(<15 \mathrm{wt} \%)$ 'MORB-like' compositions are amphibolites at $\sim 0.6-1.0 \mathrm{GPa}$ or garnet-amphibolites at $\sim 1.0-1.7 \mathrm{GPa}$ in which rutile is stable at $P>1.3$ 
$\mathrm{GPa}$, and anhydrous kyanite-bearing quartz/coesite eclogites at $P>1.7 \mathrm{GPa}$. High $\mathrm{MgO}$ compositions $(>18 \mathrm{wt} \%)$ contain olivine, orthopyroxene and ilmenite at all modelled pressures; they are metahornblendites or metapyroxenites above $\sim 0.75-0.65 \mathrm{GPa}$ to $\sim 2.3 \mathrm{GPa}$ and anhydrous garnet pyroxenites at higher pressure. For intermediate compositions (15-18 $\mathrm{wt} \% \mathrm{MgO}$ ) the upper pressure stability limit of plagioclase (and hence amphibolite) declines steeply to lower pressures with increasing $\mathrm{MgO}$. Amphibolites will begin to melt at $\sim 900{ }^{\circ} \mathrm{C}$, potentially to produce TTG-like melts. Metahornblendites and hornblende-bearing metapyroxenites will begin to melt at $\sim 1000{ }^{\circ} \mathrm{C}$, potentially to produce basalt.

In Fig. $2 \mathrm{c}$ all compositions are peridotites with $>50$ vol. $\%$ olivine and $10-30$ vol. $\%$ orthopyroxene; the abundance of both phases increases with increasing $\mathrm{MgO}$. Garnetharzburgite with trace amounts of clinopyroxene is predicted in all but the lowest $\mathrm{MgO}$ compositions at $P>1.25 \mathrm{GPa}$; spinel-bearing peridotites are stable at $P<1.2$ and additionally contain plagioclase at $P<0.8 \mathrm{GPa}$. Lherzolite with $>5$ vol.\% clinopyroxene is only stable in relatively low $\mathrm{MgO}$ residues and at $P<1.5 \mathrm{GPa}$ (because the degrees of melting are lower in this $\mathrm{X}-\mathrm{P}$ range). Also shown are contours for the forsterite content of olivine (as $\mathrm{Mg} \#=100 *$ molar $\mathrm{MgO} / \mathrm{MgO}+\mathrm{FeO}$ ), which increases from 91 to 94 with increasing $\mathrm{MgO}$.

Figures $3 \mathrm{a}$ and $\mathrm{b}$ show the calculated densities for hydrated and anhydrous primary crust calculated at $1000{ }^{\circ} \mathrm{C}$, whereas Fig. $3 \mathrm{c}$ shows the calculated densities for the complementary residues, plotted against $\mathrm{MgO}$ of the primary crust. The densities shown in these diagrams are based on the complete phase diagrams shown in Figs S1a, S3a and S5a. The residues have densities ranging from $<3200 \mathrm{~kg} / \mathrm{m}^{3}$ at low $P$ to $>3360 \mathrm{~kg} / \mathrm{m}^{3}$ at $3.5 \mathrm{GPa}$ for low $\mathrm{MgO}$ compositions. At fixed pressure, densities decrease with increasing $\mathrm{MgO}$ by up to $2 \%$ across the full compositional range modelled. Density contours for the metamorphosed primary crust are more complex reflecting the more variable mineral assemblages. For both fully hydrated and anhydrous primary crust the lowest densities occur at low $P$ and low $\mathrm{MgO}$ where the calculated abundance of plagioclase is highest. At low pressures $(<1.0 \mathrm{GPa})$, densities increase towards higher $\mathrm{MgO}$ and, at fixed pressure, may increase by $8 \%$ over the full compositional range modelled. In fully hydrated primary crust at low $\mathrm{MgO}$ compositions, density increases dramatically between 1.0 and $2.0 \mathrm{GPa}$ recording the transition from amphibolite to eclogite. In higher $\mathrm{MgO}$ compositions densities increase less dramatically with increasing pressure, recording a transition from garnet-absent to garnet-bearing metahornblendite and metapyroxenite and eventually to anhydrous garnet metapyroxenite. In anhydrous primary crust at $\mathrm{MgO}>15 \mathrm{wt} \%$ density increases dramatically from $\sim 1.0$ to $>1.3$ $\mathrm{GPa}$ recording the appearance of spinel and garnet at the expense of plagioclase, and at $\mathrm{MgO}$ $<15 \mathrm{wt} \%$ density continues to increase to $>2 \mathrm{GPa}$ as plagioclase is eliminated over a wide range of pressure. Figures $\mathrm{S} 7 \mathrm{a}$ and $\mathrm{b}$ show the calculated densities for hydrated and anhydrous primary crust calculated at $900{ }^{\circ} \mathrm{C}$, whereas Fig. S7c shows the calculated densities for the complementary residues, plotted against $\mathrm{MgO}$ of the primary crust. The densities shown in these diagrams are based on the complete phase diagrams shown in Figs S2a, S4a and S6a. The changes in density from 1000 to $900{ }^{\circ} \mathrm{C}$ are relatively small. Figure $3 \mathrm{~d}$ shows the relative density of the metamorphosed fully hydrated primary crust with respect to the underlying residual mantle at $1000^{\circ} \mathrm{C}$ plotted against $\mathrm{MgO}$ of the primary crust with the equality line for anhydrous crust at $1000^{\circ} \mathrm{C}$ and those for $900{ }^{\circ} \mathrm{C}$ (based on Supplementary Fig. S7d) superimposed. The solid (hydrated) and dashed (anhydrous) lines separate stable primary crust (below) from potentially unstable primary crust (above). 

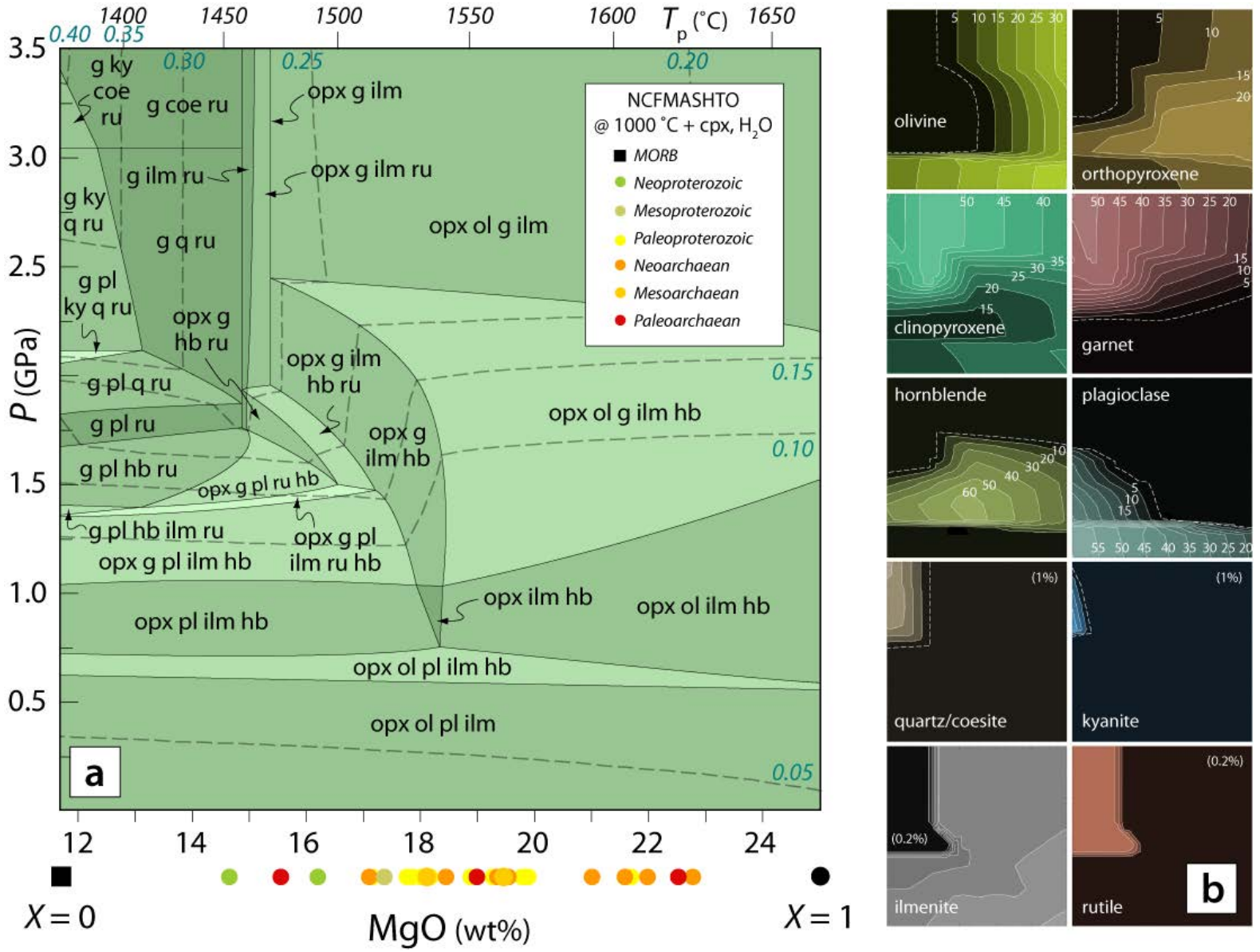

Figure S1. a, Calculated isothermal $\left(T=1000^{\circ} \mathrm{C}\right) P-X$ pseudosection in the NCFMASHTO chemical system showing the equilibrium (minimum Gibb's free energy) mineral assemblages developed within hydrated primary crust ranging in pressure from $0-3.5 \mathrm{GPa}$ and in composition from the calculated primary melt composition of MORB $(X=0)$ to a fictive end member with $25 \mathrm{wt} \% \mathrm{MgO}(X=1)$, together with the equivalent mantle potential temperatures $\left(T_{\mathrm{p}}\right.$; Herzberg et al., 2010). The extrapolated peak pressures at $1000{ }^{\circ} \mathrm{C}$ based on the apparent thermal gradients recorded by metamorphosed Precambrian rocks are also shown (Brown, 2007). The pseudosection is contoured for the mole fraction of the jadeite component in clinopyroxene (dashed lines). All fields are $\mathrm{H}_{2} \mathrm{O}$-saturated and all contain clinopyroxene in addition to those minerals listed on the diagram. Abbreviations for modelled phases are as follows: olivine (ol), garnet (g), clinopyroxene (cpx), orthopyroxene (opx), hornblende (hb), plagioclase (pl), quartz (q), ilmenite (ilm), rutile (ru), spinel (sp), magnetite (mt), hematite (hem) and $\mathrm{H}_{2} \mathrm{O}$. The depth of shading of the assemblage fields reflects increasing variance; the palest fields have a variance of 3. All phase diagrams were calculated using the software Perple_X (Connolly, 2005). Calculations use the ds55 internally consistent thermodynamic dataset (Holland \& Powell, 1998) and the most recently calibrated activity-composition models (Diener \& Powell, 2012). b, Calculated modal abundance (in vol.\%) of phases within the modelled primary crust. The pressures and binary compositional range are the same as in a. The intervals between vol.\% contours for the minor phases quartz/coesite, kyanite, ilmenite and rutile are indicated. 


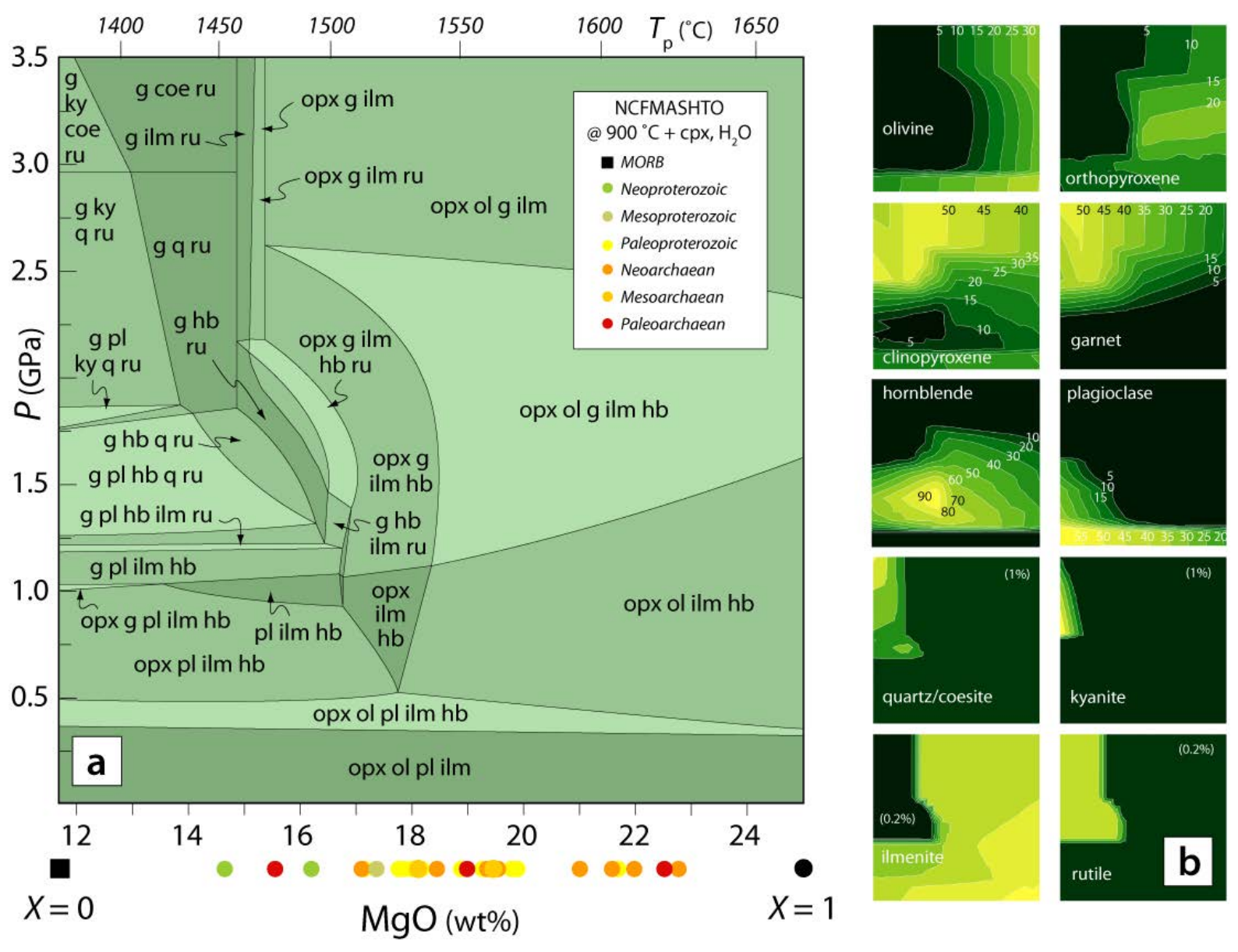

Figure S2. a, Calculated isothermal $\left(T=900^{\circ} \mathrm{C}\right) P-X$ pseudosection in the NCFMASHTO chemical system showing the equilibrium (minimum Gibb's free energy) mineral assemblages developed within hydrated primary crust ranging in pressure from $0-3.5 \mathrm{GPa}$ and in composition from the calculated primary melt composition of $\operatorname{MORB}(X=0)$ to a fictive end member with $25 \mathrm{wt} \% \mathrm{MgO}(X=1)$, together with the equivalent mantle potential temperatures $\left(T_{\mathrm{p}}\right.$; Herzberg et al., 2010). The extrapolated peak pressures at $1000{ }^{\circ} \mathrm{C}$ based on the apparent thermal gradients recorded by metamorphosed Precambrian rocks are also shown (Brown, 2007). All fields are $\mathrm{H}_{2} \mathrm{O}$-saturated and all contain clinopyroxene in addition to those minerals listed on the diagram. Abbreviations for modelled phases are as follows: olivine (ol), garnet (g), clinopyroxene (cpx), orthopyroxene (opx), hornblende (hb), plagioclase (pl), quartz (q), ilmenite (ilm), rutile (ru), spinel (sp), magnetite (mt), hematite (hem) and $\mathrm{H}_{2} \mathrm{O}$. The depth of shading of the assemblage fields reflects increasing variance; the palest fields have a variance of 3. All phase diagrams were calculated using the software Perple_X (Connolly, 2005). Calculations use the ds55 internally consistent thermodynamic dataset (Holland \& Powell, 1998) and the most recently calibrated activity-composition models (Diener \& Powell, 2012). b, Calculated modal abundance (in vol.\%) of phases within the modelled primary crust. The pressures and binary compositional range are the same as in a. The intervals between vol.\% contours for the minor phases quartz/coesite, kyanite, ilmenite and rutile are indicated. 

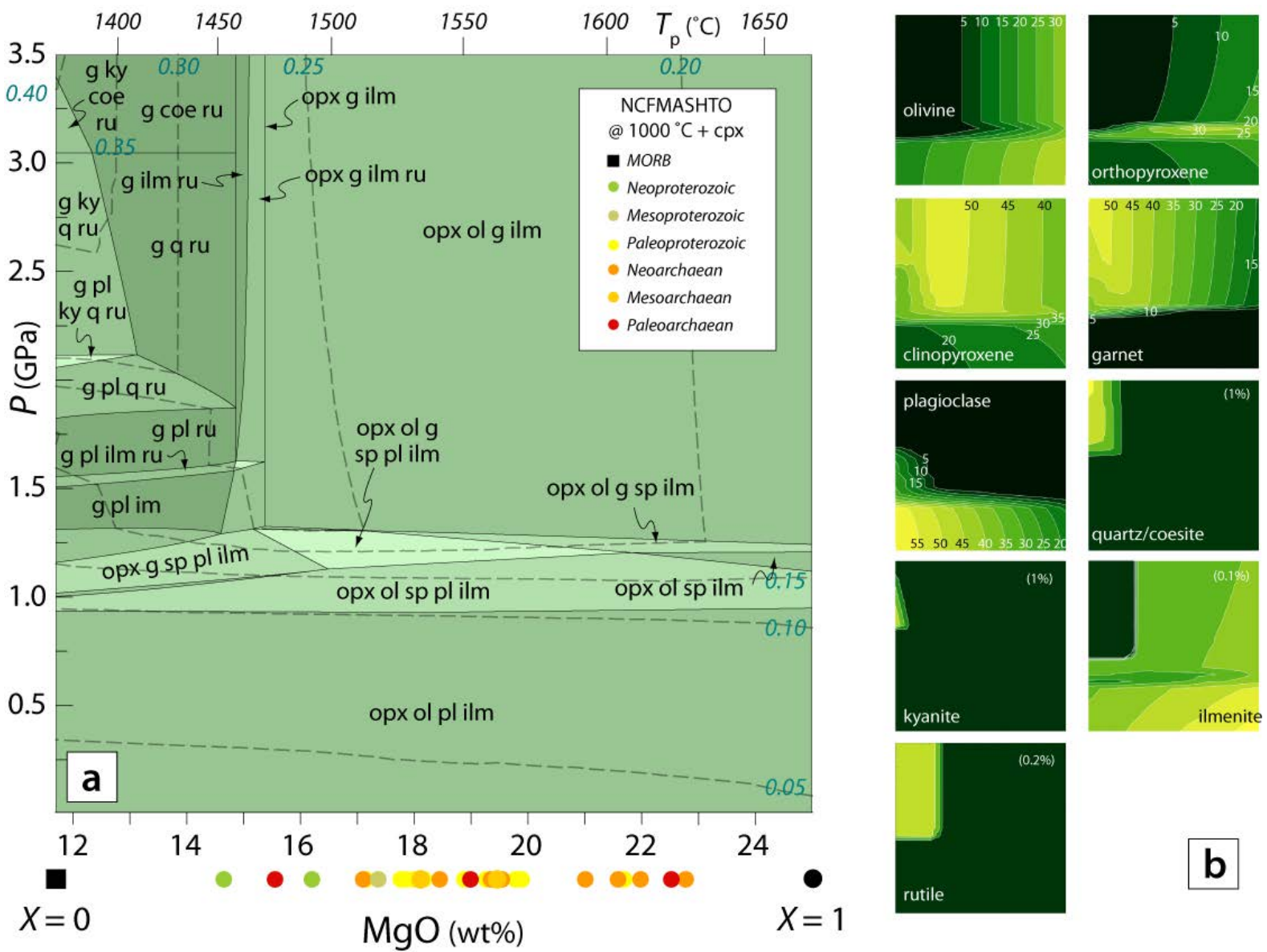

Figure S3. a, Calculated isothermal $\left(T=1000^{\circ} \mathrm{C}\right) P-X$ pseudosection in the NCFMASHTO chemical system showing the equilibrium (minimum Gibb's free energy) mineral assemblages developed within anhydrous primary crust ranging in pressure from 0-3.5 $\mathrm{GPa}$ and in composition from the calculated primary melt composition of MORB $(X=0)$ to a fictive end member with $25 \mathrm{wt} \% \mathrm{MgO}(X=1)$, together with the equivalent mantle potential temperatures $\left(T_{\mathrm{p}}\right.$; Herzberg et al., 2010). The extrapolated peak pressures at $1000{ }^{\circ} \mathrm{C}$ based on the apparent thermal gradients recorded by metamorphosed Precambrian rocks are also shown (Brown, 2007). All fields contain clinopyroxene in addition to those minerals listed on the diagram. Abbreviations for modelled phases are as follows: olivine (ol), garnet (g), clinopyroxene (cpx), orthopyroxene (opx), plagioclase (pl), quartz (q), ilmenite (ilm), rutile (ru), spinel (sp), magnetite (mt), and hematite (hem). The depth of shading of the assemblage fields reflects increasing variance; the palest fields have a variance of 3 . All phase diagrams were calculated using the software Perple_X (Connolly, 2005). Calculations use the ds55 internally consistent thermodynamic dataset (Holland \& Powell, 1998) and the most recently calibrated activity-composition models (Diener \& Powell, 2012). b, Calculated modal abundance (in vol.\%) of phases within the modelled primary crust. The pressures and binary compositional range are the same as in a. The intervals between vol.\% contours for the minor phases quartz/coesite, kyanite, ilmenite and rutile are indicated. 


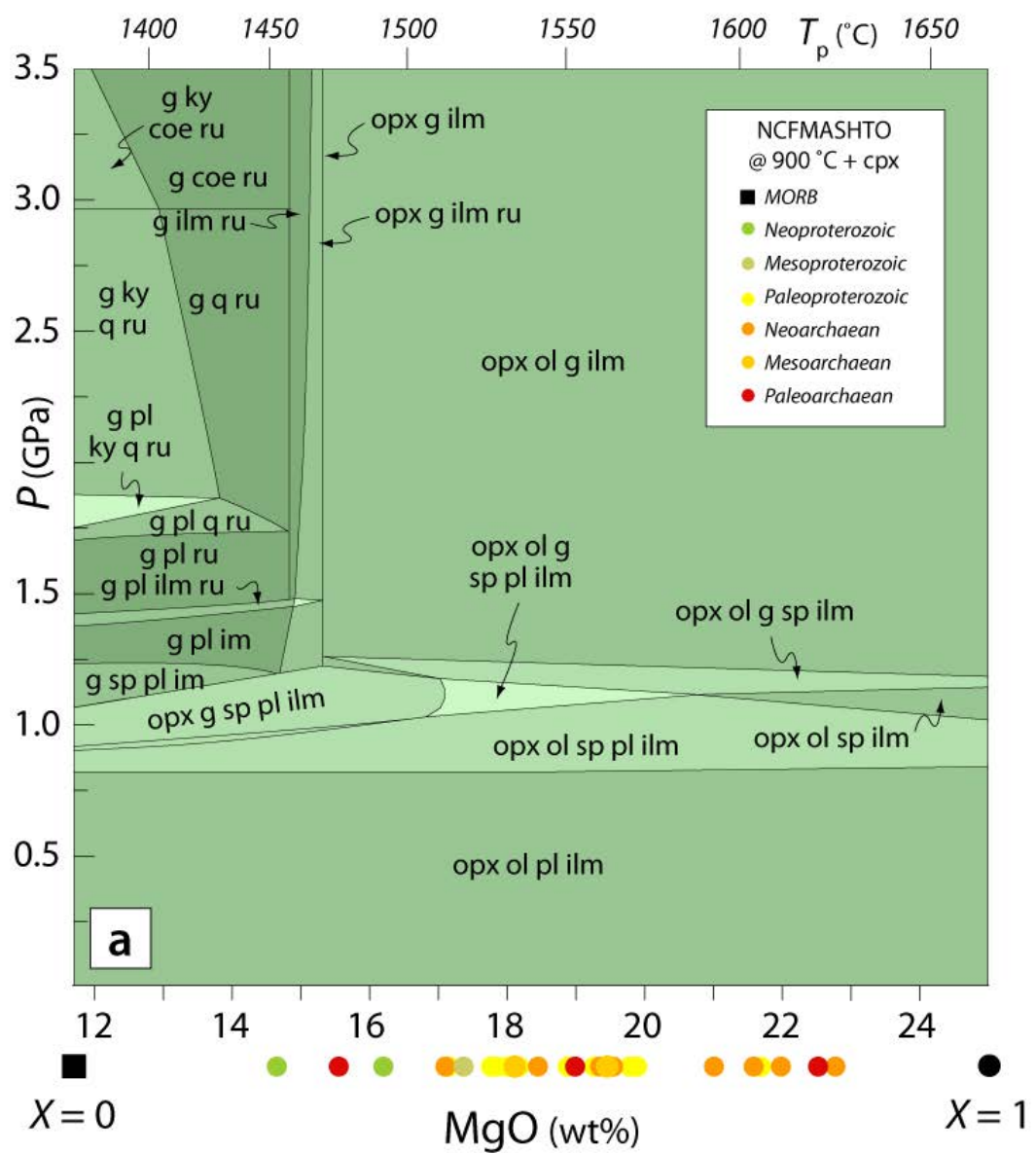

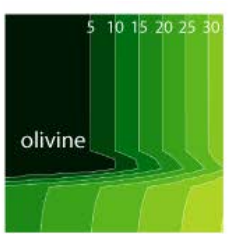
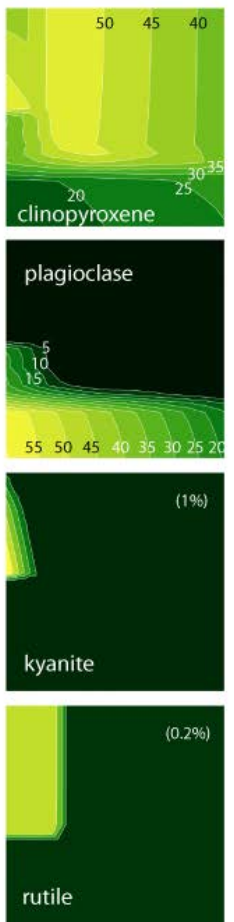
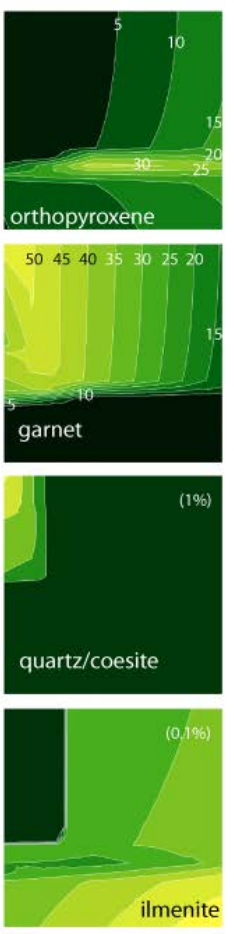

b

Figure S4. a, Calculated isothermal $\left(T=900^{\circ} \mathrm{C}\right) P-X$ pseudosection in the NCFMASHTO chemical system showing the equilibrium (minimum Gibb's free energy) mineral assemblages developed within hydrated primary crust ranging in pressure from $0-3.5 \mathrm{GPa}$ and in composition from the calculated primary melt composition of $\operatorname{MORB}(X=0)$ to a fictive end member with $25 \mathrm{wt} \% \mathrm{MgO}(X=1)$, together with the equivalent mantle potential temperatures $\left(T_{\mathrm{p}}\right.$; Herzberg et al., 2010). The extrapolated peak pressures at $1000{ }^{\circ} \mathrm{C}$ based on the apparent thermal gradients recorded by metamorphosed Precambrian rocks are also shown (Brown, 2007). All fields contain clinopyroxene in addition to those minerals listed on the diagram. Abbreviations for modelled phases are as follows: olivine (ol), garnet (g), clinopyroxene (cpx), orthopyroxene (opx), plagioclase (pl), quartz (q), ilmenite (ilm), rutile (ru), spinel (sp), magnetite ( $\mathrm{mt})$, and hematite (hem). The depth of shading of the assemblage fields reflects increasing variance; the palest fields have a variance of 3 . All phase diagrams were calculated using the software Perple_X (Connolly, 2005). Calculations use the ds55 internally consistent thermodynamic dataset (Holland \& Powell, 1998) and the most recently calibrated activity-composition models (Diener \& Powell, 2012). b, Calculated modal abundance (in vol.\%) of phases within the modelled primary crust. The pressures and binary compositional range are the same as in a. The intervals between vol.\% contours for the minor phases quartz/coesite, kyanite, ilmenite and rutile are indicated. 


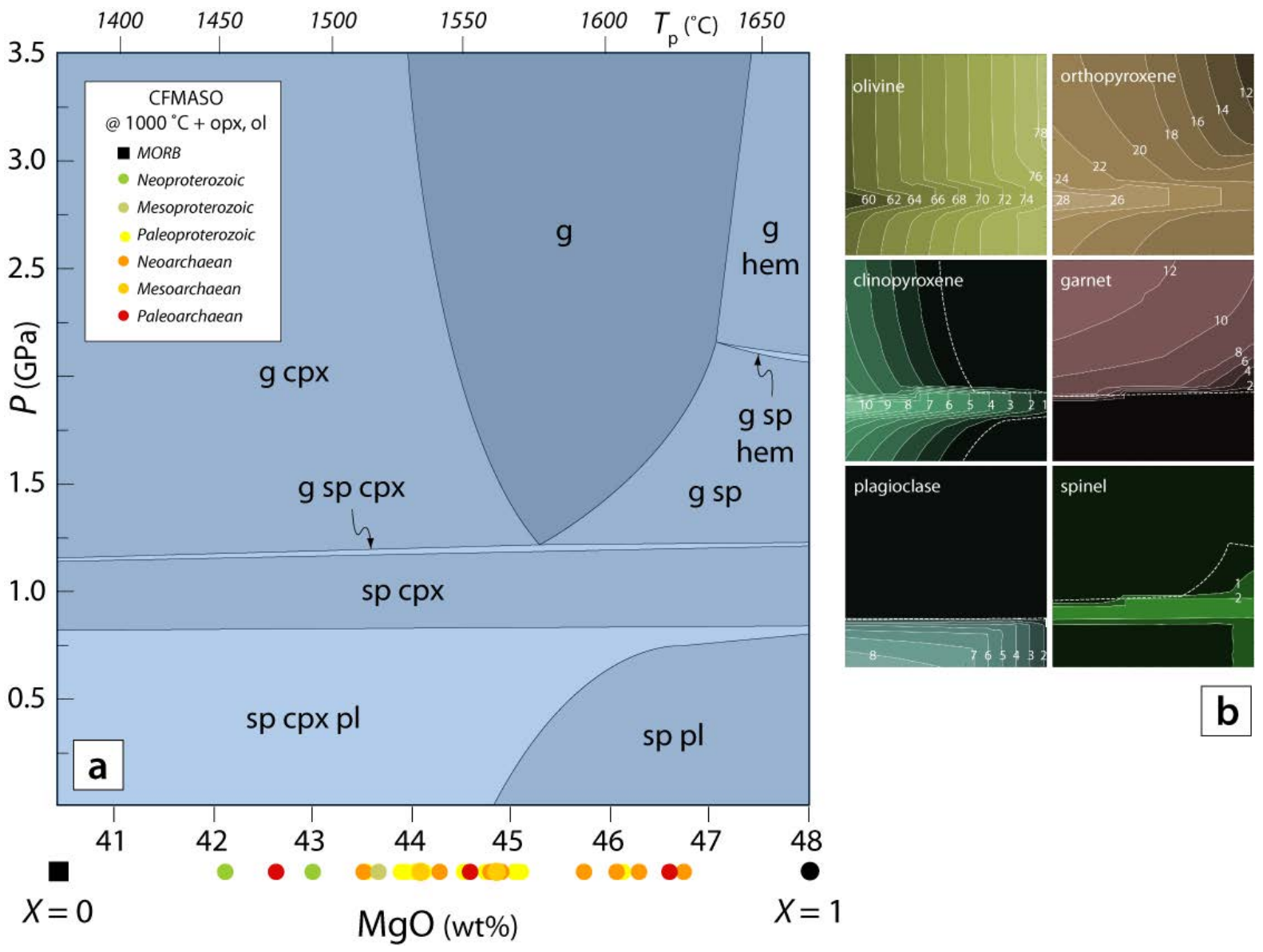

Figure S5. a, Calculated isothermal $\left(T=1000{ }^{\circ} \mathrm{C}\right) P-X$ pseudosection in the CFMASO chemical system showing the equilibrium (minimum Gibb's free energy) mineral assemblages developed within mantle residues ranging in pressure from $0-3.5 \mathrm{GPa}$ and in composition from the calculated residue composition of MORB $(X=$ $0)$ to that of a fictive end member with $48 \mathrm{wt} \% \mathrm{MgO}(X=1)$, together with the equivalent mantle potential temperatures $\left(T_{\mathrm{p}}\right.$; Herzberg et al., 2010). The extrapolated peak pressures at $1000{ }^{\circ} \mathrm{C}$ based on the apparent thermal gradients recorded by metamorphosed Precambrian rocks are also shown (Brown, 2007). All fields contain orthopyroxene and olivine in addition to those minerals listed on the diagram. Abbreviations for modelled phases are as follows: garnet (g), clinopyroxene (cpx), plagioclase (pl), and hematite (hem). The depth of shading of the assemblage fields reflects increasing variance; the palest fields have a variance of 4 . All phase diagrams were calculated using the software Perple_X (Connolly, 2005). Calculations use the ds55 internally consistent thermodynamic dataset (Holland \& Powell, 1998) and the most recently calibrated activitycomposition models (Diener \& Powell, 2012). b, Calculated modal abundance (in vol.\%) of phases within the modelled mantle residues. The pressures and binary compositional range are the same as in a. 


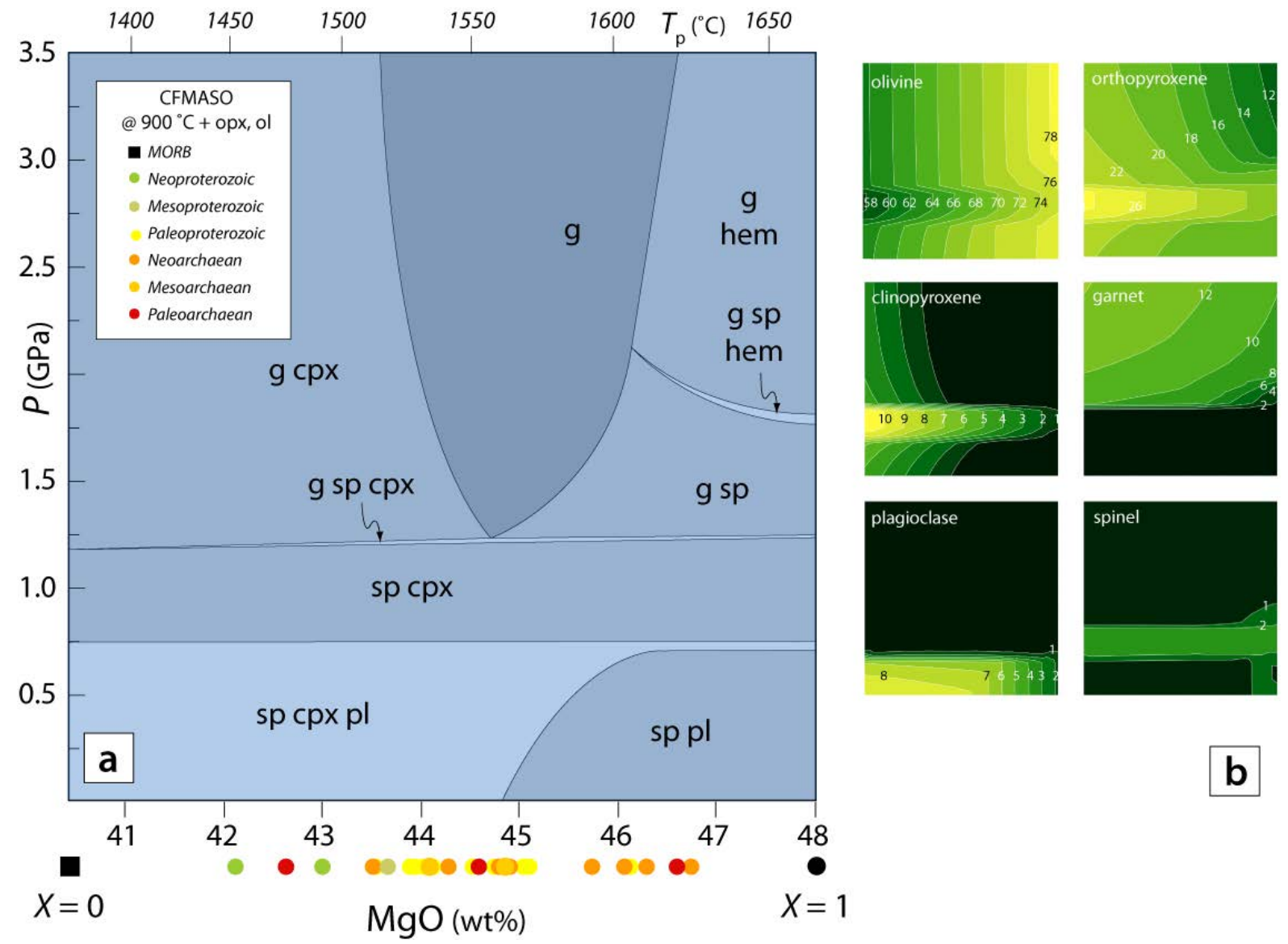

Figure S6. a, Calculated isothermal $\left(T=900^{\circ} \mathrm{C}\right) P-X$ pseudosection in the CFMASO chemical system showing the equilibrium (minimum Gibb's free energy) mineral assemblages developed within mantle residues ranging in pressure from 0-3.5 GPa and in composition from the calculated residue composition of MORB $(X=0)$ to that of a fictive end member with $48 \mathrm{wt} \% \mathrm{MgO}(X=1)$, together with the equivalent mantle potential temperatures $\left(T_{\mathrm{p}}\right.$; Herzberg et al., 2010). The extrapolated peak pressures at $1000{ }^{\circ} \mathrm{C}$ based on the apparent thermal gradients recorded by metamorphosed Precambrian rocks are also shown (Brown, 2007). All fields contain orthopyroxene and olivine in addition to those minerals listed on the diagram. Abbreviations for modelled phases are as follows: garnet $(\mathrm{g})$, clinopyroxene $(\mathrm{cpx})$, plagioclase $(\mathrm{pl})$, and hematite (hem). The depth of shading of the assemblage fields reflects increasing variance; the palest fields have a variance of 4 . All phase diagrams were calculated using the software Perple_X (Connolly, 2005). Calculations use the ds55 internally consistent thermodynamic dataset (Holland \& Powell, 1998) and the most recently calibrated activity-composition models (Diener \& Powell, 2012). b, Calculated modal abundance (in vol.\%) of phases within the modelled mantle residues. The pressures and binary compositional range are the same as in a. 

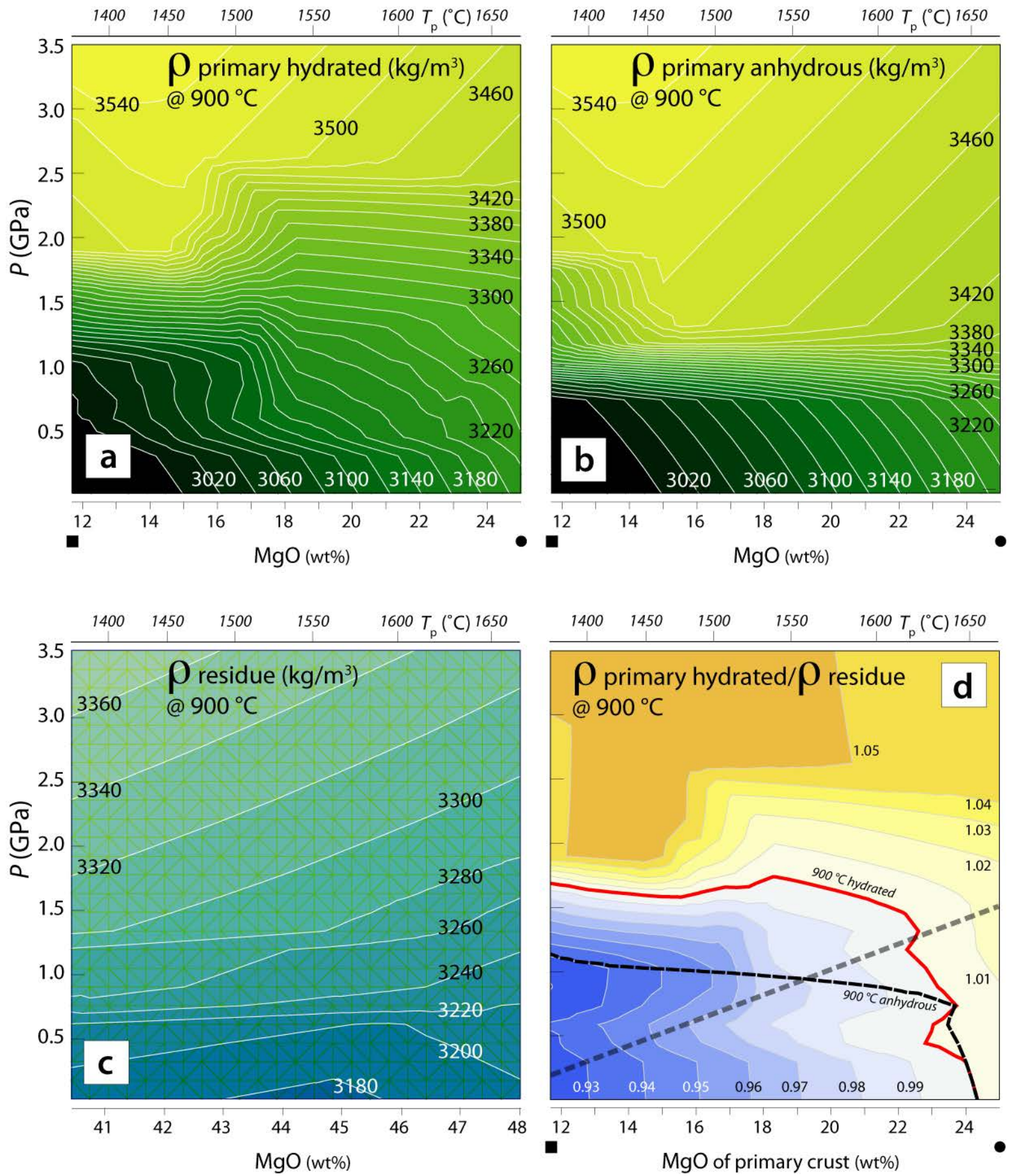

Figure S7. Density of primary crust and complementary residues. Densities calculated at $900{ }^{\circ} \mathrm{C}$ plotted against $\mathrm{MgO}$ content for $\mathbf{a}$, hydrated primary crust, $\mathbf{b}$, anhydrous primary crust and $\mathbf{c}$, the complementary residues. d, Shows the relative density of hydrated crust compared to the underlying residual mantle at $900{ }^{\circ} \mathrm{C}$ against $\mathrm{MgO}$ of the primary crust with the equality line for anhydrous crust at $900{ }^{\circ} \mathrm{C}$ superimposed. The solid (hydrated) and dashed (anhydrous) lines separate stable primary crust (below) from potentially unstable primary crust (above). 


\section{Geodynamic numerical modelling}

\subsection{Background}

The numerical code employed for the geodynamic simulations has been described in detail elsewhere (Kaus, 2010; Thielmann \& Kaus, 2012; Schmeling et al., 2008). For completeness, a brief summary is provided here together with a description of several new features added to the code for the present study, namely melt extraction and evolution.

\subsubsection{Governing equations and numerical approach}

The incompressible Stokes system of equations are given by

$$
\begin{aligned}
& \frac{\partial v_{i}}{\partial x_{i}}=0 \\
& -\frac{\partial P}{\partial x_{i}}+\frac{\partial \tau_{i j}}{\partial x_{j}}=\rho g_{i} \\
& \rho c_{p}\left(\frac{\partial T}{\partial t}+v_{i} \frac{\partial T}{\partial x_{i}}\right)=\frac{\partial}{\partial x_{i}}\left(k \frac{\partial T}{\partial x_{i}}\right)+\tau_{i j} \dot{\varepsilon}_{i j}-\alpha T \rho g v_{2}
\end{aligned}
$$

Where $v_{\mathrm{i}}$ indicates velocity, $P$ pressure, $\tau_{i j}$ deviatoric stresses, $g_{i}$ gravitational acceleration, $\rho$ density, $c_{p}$ heat capacity, $T$ temperature, $k$ thermal conductivity, $\varepsilon_{i j}$ strain rate, and $\alpha$ thermal expansivity, and the Einstein notation is used and both shear heating and adiabatic (de)compression are taken into account in the energy equation.

Density in the models is a function of rock type/composition $(X)$, melt fraction $(M)$, pressure $(P)$ and temperature $(T)$ :

$\rho=f(X, M, P, T)$

A viscoplastic constitutive relationship is used, as follows

$$
\begin{aligned}
\tau_{i j} & =2 \eta_{e f f} \dot{\varepsilon}_{i j} \\
\eta_{e f f} & =\min \left(\eta_{\text {diff }}, \eta_{\text {disl }}, \eta_{\text {yield }}\right)
\end{aligned}
$$

in which the dominant rheology is diffusion creep, dislocation creep or plastic yielding, as given by

$\eta_{\text {diff }}=\eta_{0, \text { diff }} \exp \left(Q_{\text {diff }}\left(\frac{1}{T}-\frac{1}{873}\right)\right)$ 
$\eta_{d i s l}=\eta_{0, \text { disl }}\left(\frac{\dot{\varepsilon}_{I I}}{10^{-15}}\right)^{\frac{1}{n}-1} \exp \left(Q_{\text {disl }}\left(\frac{1}{T}-\frac{1}{873}\right)\right)$

$\eta_{y i e l d}=\frac{\sigma_{y i e l d}}{2 \dot{\varepsilon}_{I I}}$

where $\sigma_{\text {yield }}$ is the yield stress, $\varepsilon_{I I}$ the second invariant of the strain rate tensor, $\eta_{0}$ the effective viscosity at $873 \mathrm{~K}$ and $10^{-15} \mathrm{~s}^{-1}, n$ the power law exponent and $Q$ the temperaturedependency of viscosity. For mantle rocks we take diffusion and dislocation creep into account for both "wet" and "dry" end-members whereas the crust is assumed to have a diabase dislocation creep rheology. Density depends on the rock-type, melt fraction and the pressure-temperature conditions, as described in more detail below.

The governing equations are solved with the 2D finite element code MILAMIN_VEP, and we employ LBB stable $\mathrm{Q}_{2} \mathrm{P}_{-1}$ elements for the Stokes equations and quadratic elements for temperature. The code is written in MATLAB, but nevertheless is made relatively efficient by employing the techniques described in detail in Dabrowski et al. (2008). Tracers are used to track material properties and the code is used in an ALE mode with regular remeshing to ensure that elements do not become too distorted. This code has been benchmarked for a large number of test problems including convection, Rayleigh-Taylor instabilities, thermal diffusion, shear-heating, and multilayer folding, as well as versus various analytical solutions (e.g. SolCx or weak/strong inclusion setups), as described in a number of publications (Gerya \& Yuen, 2007; May \& Moresi, 2008; Schmeling et al., 2008; Crameri \& Kaus, 2010; Yamato et al., 2011; Crameri et al., 2012; Thielmann \& Kaus, 2012).

\subsubsection{Phase transitions and partial melting}

The variations of crustal density as a function of $P$ and $T$ is computed with Perple_X, as described in the main text. We discriminate between initial crust, which has a composition with $23 \mathrm{wt} \% \mathrm{MgO}$ (at $X=0.839$ on the binary mixture for the NCFMASHTO modelled primary crust given in the Methods) and "new crust", which has a composition with $13 \mathrm{wt} \%$ $\mathrm{MgO}$ (at $X=0.104$ on the binary mixture for the NCFMASHTO modelled primary crust given in the Methods).

We take into account two types of mantle: lithospheric mantle, which is the residual mantle leftover after forming the initial crust (i.e. it has a composition at $X=0.839$ on the binary mixture for the CFMASO modelled residua given in the Methods), and underlying asthenospheric mantle, which is more fertile than the lithospheric mantle and has the CFMASO model composition of KR-4003 (Herzberg et al. 2010). For both mantle lithologies, initially the density is computed as a function of $P$ and $T$ without melting using Perple_X. In a next step, pMELTS (Ghiorso et al., 2002) is used to estimate the solidus and liquidus temperatures as well as melt fractions for both (depleted) lithospheric mantle and asthenosphere. Although this gives reliable estimates, pMELTS is only well-calibrated for pressures between 1 and $3 \mathrm{GPa}$ and melt fractions smaller than 0.3 , whereas the models in this study require information from 0-10 GPa or higher. Therefore, for the fertile asthenospheric mantle the parameterization of Katz et al. (2003) is used, but adapted for the appropriate Cpx modal fractions for the composition used. For the more depleted mantle lithosphere, the parameterization of Katz et al. (2003) is not well calibrated (as too few 
experiments exist), and therefore we rely solely on pMELTS data that have been extrapolated to higher and lower pressures, after adapting the solidus and liquidus parameterization for Katz et al. (2003) to fit the pMELTS data in the validity range. In common with most simulations, the lithospheric mantle does not melt extensively; this does not have a large impact on the results of this study, but future experimental work is nevertheless required to better constrain the parameterization.

Melting of crustal rocks is not taken into account in the geodynamic modelling, because a thermodynamic model is not currently available to reliably predict the $P-T$ relations of the solidus and liquidus for these crustal compositions, although, if fully hydrated, one might expect crustal rocks of the compositions modelled in this study to melt above temperatures of $1000{ }^{\circ} \mathrm{C}$. The absence of melting in the crust is a crude first-order approximation. However, we do not expect the inclusion of crustal melting to significantly alter model outcomes because this will produce both melt and residue, and the latter will be even denser than the densities already used, so the drips will likely continue descending into the mantle.

\subsubsection{Melting and melt extraction}

In reality, melt will be extracted by a variety of mechanisms, such as diking or compaction-driven flow. As these processes mostly happen on a timescale that is significantly smaller than the typical time step employed in the model, we assume that melt in the mantle is extracted instantaneously and emplaced on top of the crust. In doing this the possibility that melt might be trapped in the crust during ascent is ignored, which is justified as both mechanisms will thicken the crust.

The melt extraction algorithm largely follows the approach of Sizova et al. (2010), and is done in several steps, as follows.

1) The theoretical melt fraction $M_{0}$ of a given rock is computed, which depends on the composition of the rock (asthenosphere or mantle lithosphere), the $P-T$ condition and the melting diagram, which is a lookup table as a function of $P, T$. In general, melt fractions do not vary linearly between solidus and liquidus, but instead change nonlinearly and in a stepwise manner, for example once Cpx in the rock is consumed (Katz et al., 2003).

2) It is assumed that melt will be extracted once the melt fraction exceeds a critical extraction melt fraction $\left(M_{\text {extract }}\right)$, which is set as 0.05 in this work. After a melt-extraction event, a small amount of non-extractable melt $\left(M_{m i n}\right)$ will remain in the rock, which is here taken as 0.02 .

3) The amount of melt that has been extracted is tracked on markers. The amount of melt currently present at each marker takes into account melt that has been extracted from that marker during earlier melt extraction events, and is computed as

$$
M=M_{0}-\sum_{n} M_{e x t}
$$

where $\sum_{n} M_{e x t}$ is the total amount of melt extracted in the previous $n$ melt extraction events. 
4) If $M>M_{\text {extract }}$, the extractable melt fraction $M_{\text {ext }}=M-M_{\min }$ moves upwards to create new crust and the remaining melt fraction in the mantle $(M)$ is updated. Simultaneously, the remaining rock will have a reduced volume $1-M_{\text {ext }}$, which is compensated by compaction in the vertical direction. This is computed by interpolating the irregular marker distribution on a regular grid on which the vertical motion due to compaction as well as the thickness of the newly formed crust is calculated for every horizontal grid cell. New markers are randomly inserted in the newly generated crust and existing markers are moved downwards accordingly. The newly formed crust, which typically has a thickness of a few 100 meters, will initially be hot (and have mantle temperature) but will cool rapidly on a timescale smaller than the typical time step used (a few 1000 years). For simplicity, therefore, we assume the temperature of the newly formed crust to be $700{ }^{\circ} \mathrm{C}$. Since the characteristic diffusion time for the new crust is typically smaller than the time step, and the new magma is assumed to be emplaced at the surface where gradients in temperature are large, the precise temperature of the new crust does not have a major impact on the results,. This simplification was verified by performing additional calculations in which the emplacement temperature was varied from 20 to $900{ }^{\circ} \mathrm{C}$; these experiments yielded similar results. A more sophisticated approach, in which one would model every magmatic pulse with, for example, a 1-D temperature profile, is expected to have little effect on the key results and was not employed here.

5) If more than a certain amount of melt is extracted from a tracer $\left(M_{\max }\right)$, the rock is assumed to be depleted and no longer produces melt.

6) The effective density of the remaining partially molten mantle rock is computed according to $\rho=M \rho_{\text {melt }}+(1-M) \rho_{\text {phasediagram }}$ where $\rho_{\text {melt }}$ is the density of the melt, which is assumed to have a constant value of $2800 \mathrm{~kg} / \mathrm{m}^{3}$ for simplicity, although we note this is in good agreement with estimates from pMELTS calculations, and $\rho_{\text {phasediagram }}$ is the density taken from the phase diagram without partial melting.

The effective viscosity of a partially molten region depends on the melt fraction in a nonlinear fashion (e.g., Bittner, \& Schmeling, 1995; Deubelbeiss et al., 2010). As the mafic melts produced in our model are likely to have had a very low viscosity, similar to that of present-day basaltic melts (on the order of $1 \mathrm{~Pa} \mathrm{~s}$ ), and the melting typically occurs in regions of the asthenosphere which already have a low solid viscosity, the effective viscosity of the partially molten rock (with no more than 5 vol. \% melt in the experiments) is likely to be lower than cut-off viscosity employed. Therefore, a constant viscosity of $10^{18}$ Pas is assigned to regions that are partially molten.

\subsubsection{Model setup}

The model consists of a 2D box that is $1000 \mathrm{~km}$ wide and $660 \mathrm{~km}$ high, and has an initial crust of variable thickness, an underlying depleted mantle lithosphere up to a depth of $100 \mathrm{~km}$, and an underlying fertile asthenosphere. Mechanical boundary conditions are free slip (shear stress free) on the side and top boundaries, and no-slip on the bottom boundary, which mimics a viscosity increase in the lower mantle compared to that of the upper mantle. Thermal boundary conditions are isothermal at the top and bottom (in accordance with the initial geotherm) and flux-free at the side boundaries. As the initial geotherm in the Archaean is uncertain and has evolved dynamically, we use a simplistic approach by assuming it to be initially linear in the crust, with $20^{\circ} \mathrm{C}$ at the surface and $1000^{\circ} \mathrm{C}$ at the Moho, and linearly increasing below until it intersects the mantle adiabat at a depth of $100 \mathrm{~km}$. The mantle adiabat is computed based on $T_{p}$ (which is varied in the simulations) and an increase of 0.3 
$\mathrm{K} / \mathrm{km}$. The temperature condition at the bottom of the model is computed from the mantle adiabat. An overview of model parameters is given in Table S1.

The model employs a computational mesh of $257 \times 257$ nodes, which is refined towards the lithosphere, such that there is a resolution of $3.9 \mathrm{~km}$ (horizontal) by $2.1 \mathrm{~km}$ (vertical) in the lithosphere and 3.9 by $3.2 \mathrm{~km}$ below a depth of $330 \mathrm{~km}$. Compositions are tracked on tracers of which there are initially $\sim 0.8$ million, which number increases during the simulation as new crust is formed. To initiate convection, random noise with a maximum amplitude of $5{ }^{\circ} \mathrm{C}$ is initially added on tracers that are deeper than $130 \mathrm{~km}$. As in any geodynamic model with tracers, the fine scale mixing structure in the mantle that occurs in the later stages of the model is not well resolved and should not be interpreted literally (Tackley \& King, 2003). The large-scale features, such as the dripping instabilities at the bottom of the lithosphere, are considered to be robust, as tests with a smaller numerical resolution and fewer particles give similar results.

Earth has a free surface, rather than a free slip upper boundary condition as in the experiments. A simulation with standard parameters and a free surface condition was performed to test the effect of this difference on the model dynamics; the result was that the surface condition had a negligible effect on the model dynamics. Surface topographies are typically less than a kilometre in amplitude.

With the chosen geotherm, the asthenosphere immediately underneath the mantle lithosphere is initially partially molten, which results in the formation of a thin layer of new crust at the onset of the simulation (with thicknesses of 2,5 and $10 \mathrm{~km}$ for simulations with a $45 \mathrm{~km}$ thick initial crust and a mantle $T_{p}$ of 1500,1550 and $1600^{\circ} \mathrm{C}$, respectively). This is a model artefact as in reality the crust would thicken in a dynamic manner and potentially dripoff at the bottom while growing at the top. Notwithstanding, the subsequent evolution of the models is robust, with new crust preferentially forming above upwellings. Moreover, as shown below, models with thinner initial crust produce similar results. Other modelling choices are possible, such as starting with an initially partially depleted asthenosphere, but this is considered unlikely to change the overall findings of the modelling we report herein. 


\begin{tabular}{|c|c|c|}
\hline Parameter & Value & Units \\
\hline Thermal conductivity $k$ & 3 & $\mathrm{~W} / \mathrm{m} / \mathrm{K}$ \\
\hline Heat capacity $c_{p}$ & 1050 & $\mathrm{~J} / \mathrm{kg} / \mathrm{K}$ \\
\hline Gravitational acceleration $g$ & 9.81 & $\mathrm{~m} / \mathrm{s}^{2}$ \\
\hline Lower cutoff viscosity $\eta_{\min }$ & $10^{18}$ & Pas \\
\hline Upper cutoff viscosity $\eta_{\max }$ & $10^{24}$ & Pas \\
\hline Viscosity partially molten zone $\eta_{\text {moltenzone }}$ & $10^{18}$ & Pas \\
\hline Yield stress $\sigma_{\text {yield }}$ & 1000 & $\mathrm{MPa}$ \\
\hline Crust $^{1}$ : dislocation creep prefactor $\eta_{0, \text { disl }}$ & $2.3 \times 10^{21}$ & Pas \\
\hline Crust $^{1}$ : dislocation creep powerlaw exponent $n$ & 3.05 & - \\
\hline Crust $^{1}$ : temperature dependence of viscosity $Q_{\text {disl }}$ & $1.09 \times 10^{4}$ & $\mathrm{~K}$ \\
\hline Wet Mantle ${ }^{2}:$ dislocation creep prefactor $\eta 0$, disl & $1.08 \times 10^{23}$ & Pas \\
\hline Wet Mantle $^{2}$ : dislocation creep powerlaw exponent $n$ & 3.5 & - \\
\hline Wet Mantle $^{2}$ : temperature dependence of viscosity $Q_{\text {disl }}$ & $1.6 \times 10^{4}$ & $\mathrm{~K}$ \\
\hline Wet Mantle $^{2}$ : diffusion creep prefactor $\eta_{0, \text { diff }}$ & $1.1 \times 10^{29}$ & Pas \\
\hline Wet Mantle2: diffusion dependence of viscosity $Q_{\text {disl }}$ & $4.03 \times 10^{4}$ & $\mathrm{~K}$ \\
\hline Dry Mantle $^{2}$ : dislocation creep prefactor $\eta 0$, disl & $1.07 \times 10^{24}$ & Pas \\
\hline Dry Mantle2: dislocation creep powerlaw exponent $n$ & 3.5 & - \\
\hline 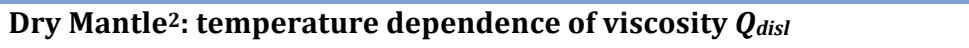 & $1.82 \times 10^{4}$ & $\mathrm{~K}$ \\
\hline Dry Mantle $^{2}:$ diffusion creep prefactor $\eta$ o,diff & $1.8 \times 10^{31}$ & Pas \\
\hline Dry Mantle²: diffusion dependence of viscosity $Q_{\text {disl }}$ & $4.5 \times 10^{4}$ & $\mathrm{~K}$ \\
\hline Minimum leftover melt fraction $\boldsymbol{M}_{\min }$ & 0.02 & - \\
\hline Extraction limit to extract melt and form new crust $M_{\text {extract }}$ & 0.05 & - \\
\hline $\begin{array}{l}\text { Maximum extractable melt fraction from the rocks, before they } \\
\text { become depleted (non-meltable) mantle rocks } M_{\max }\end{array}$ & 0.5 & - \\
\hline
\end{tabular}

Table S1. Model parameters employed in this work. ${ }^{1}$ Rheology for the crust are calculated from experiments for a dry diabase rheology as reported by Carter \& Tsenn (1987), ${ }^{2}$ wet and dry mantle dislocation and diffusion creep parameters are taken from Hirth \& Kohlstedt (2003), table 1. We assume $\mathrm{C}_{\mathrm{OH}}$ of $1000 \mathrm{H} / 10^{6} \mathrm{Si}$ for wet rheologies and a grainsize of $10 \mathrm{~mm}$ for diffusion creep. Density and melt fraction are taken from pre-computed phase diagrams.

\subsection{Geodynamic model results}

Systematic experiments have been run to test the sensitivity of the key results to changes in crustal thickness, mantle $T_{p}$, and mantle rheology (wet vs dry).

\subsubsection{Effect of initial crustal thickness}

Models with $T_{p}=1600{ }^{\circ} \mathrm{C}$, but with varying crustal thickness for a wet and dry mantle rheology (Figs S8, 9), reveal that the physical mechanism is essentially independent of the assumed initial crustal thickness. For crustal recycling to occur, the crust only needs to be 
thickened sufficiently to become negatively buoyant at its base at the same time as it becomes sufficiently weak through heating to drip off.

\subsubsection{Effect of mantle potential temperature, Moho temperature and rheology}

The effect of changing the mantle $T_{p}$ for a wet mantle rheology is illustrated in Fig. S10. Higher $T_{p}$ results in a thicker initial crust and in its more rapid removal. As in the case with $T_{p}=1600{ }^{\circ} \mathrm{C}$, the new crust is ultimately recycled into the mantle where it could partially melt (a process that was not modelled). For $T_{p}<1550{ }^{\circ} \mathrm{C}$, a tiny volume of new crust is formed at the beginning of the model runs but later during the runs partial melting no longer occurs in these experiments, and a stagnant lid mode of convection sets in (note that we did not make an attempt to model plate-like behaviour in this study, which requires the use of much smaller yield stresses).

The same analysis for a dry mantle rheology suggests that recycling of the new crust into the mantle stops at a slightly higher $T_{p}$ (between 1550 and $1600{ }^{\circ} \mathrm{C}$ ) in these experiments in comparison to those with the wet mantle rheology, but that nonetheless it is a very efficient mechanism above these temperatures (Fig. S11).

Experiments with the 'standard' setup (Fig. 4, main paper) but with different initial Moho temperature yield essentially identical results as the standard model, suggesting that the initial thermal state of the crust is a second-order effect in the experiments (Fig. S12). However, it should be noted that crustal melting is not taken into account - adding this process into the model is likely to have an effect at Moho temperatures larger than $1000{ }^{\circ} \mathrm{C}$.

In all experiments, the mantle lithosphere must be eroded and the initial crust thickened before the lower crust is heated sufficiently to generate a dripping instability. Therefore, most of the drips occur above or in the vicinity of upwelling partially molten zones in the mantle, where the newly generated crust "pushes" the older crust into warmer mantle, where it is negatively buoyant. Simultaneously, the depressed crust is heated, which results in a lower effective viscosity that allows Rayleigh-Taylor drips to form in a relatively rapid manner (in agreement with the scaling analysis shown in 3.2.3) For larger values of $T_{p}$, erosion of the mantle lithosphere occurs more efficiently, although the original crust remains present for a longer period of time above regions shielded by any leftover mantle lithosphere. At lower $T_{p}$ this effect plays a more important role and the high viscosity and relatively low density of the mantle lithosphere stabilizes the crust.

As crustal melting is not taken into account in the experiments, the results of these experiments can be regarded as providing conservative estimates on when crustal recycling occurs. Partial melting of the crust would further increase the overall thickness of the crust, which should enhance the recycling effect. 

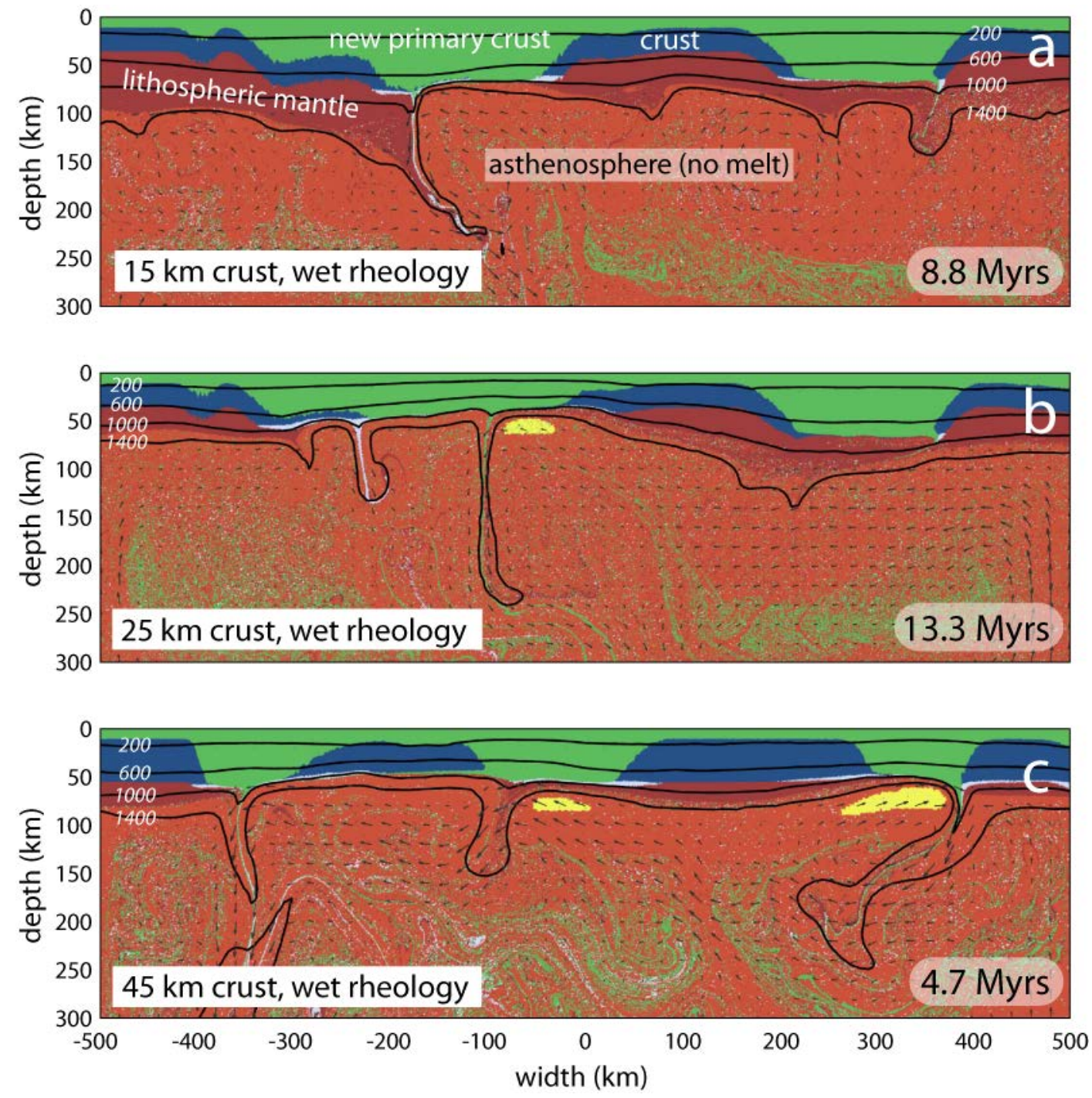

Figure S8. Snapshots from experiments with $T_{p}$ of $1600{ }^{\circ} \mathrm{C}$ and wet mantle rheology. a, Initial crustal thickness $=15 \mathrm{~km}$; b, initial crustal thickness $=25 \mathrm{~km}$; and, $\mathbf{c}$, initial crustal thickness $=45 \mathrm{~km}$. Colours: dark blue, initial primary crust; light blue, negatively buoyant initial primary crust; dark pink-brown, lithospheric mantle; light pink-brown, unmelted asthenosphere; green positively and negatively buoyant newly-created crust; and yellow, melt-bearing asthenosphere). 

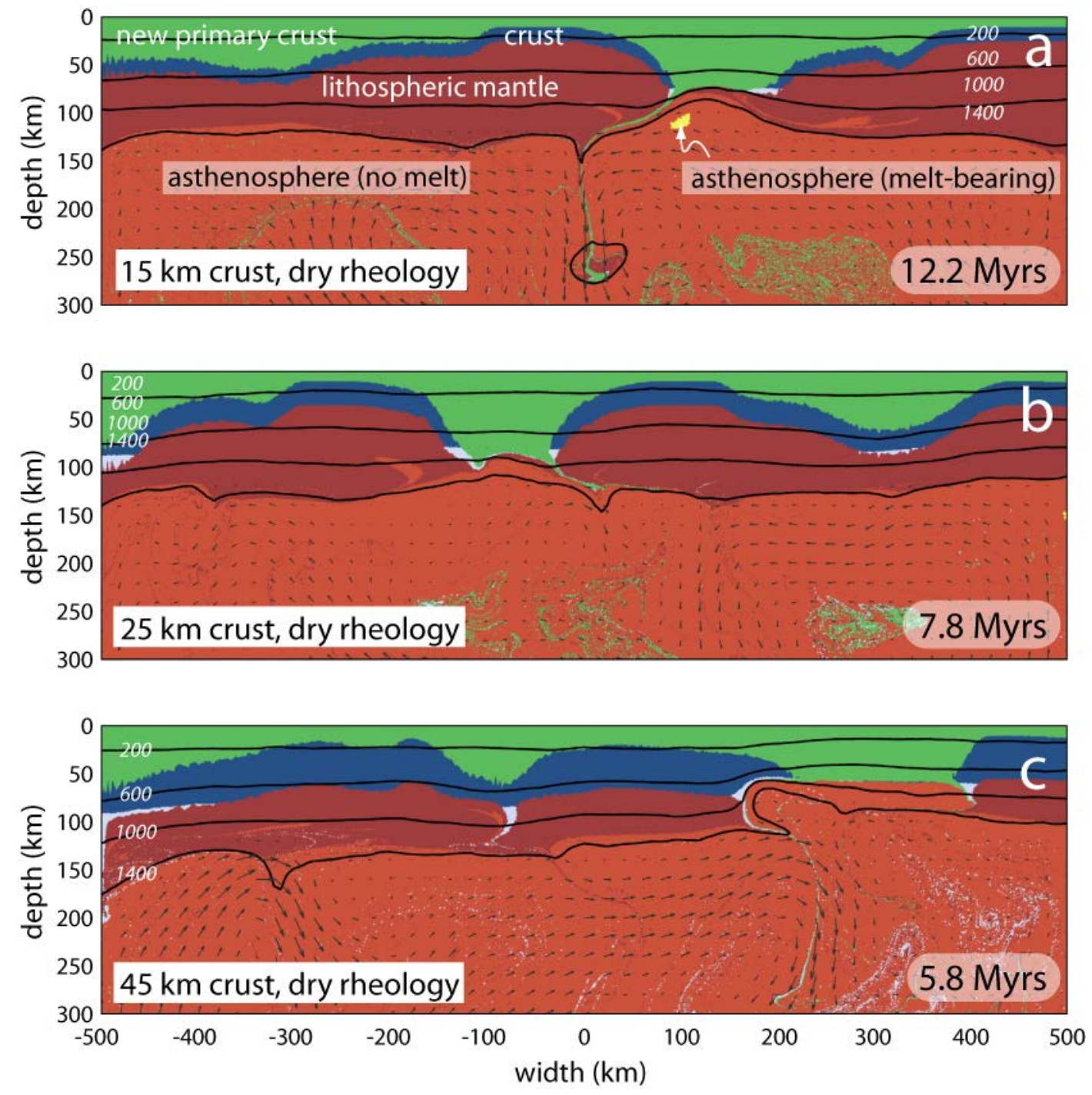

Figure S9. Snapshots from experiments with $T_{p}$ of $1600{ }^{\circ} \mathrm{C}$ and dry mantle rheology. a, Initial crustal thickness $=15 \mathrm{~km}$; b, initial crustal thickness $=25 \mathrm{~km}$; and, $\mathbf{c}$, initial crustal thickness $=45 \mathrm{~km}$. Colours: dark blue, initial primary crust; light blue, negatively buoyant initial primary crust; dark pink-brown, lithospheric mantle; light pink-brown, unmelted asthenosphere; and yellow, melt-bearing asthenosphere). 

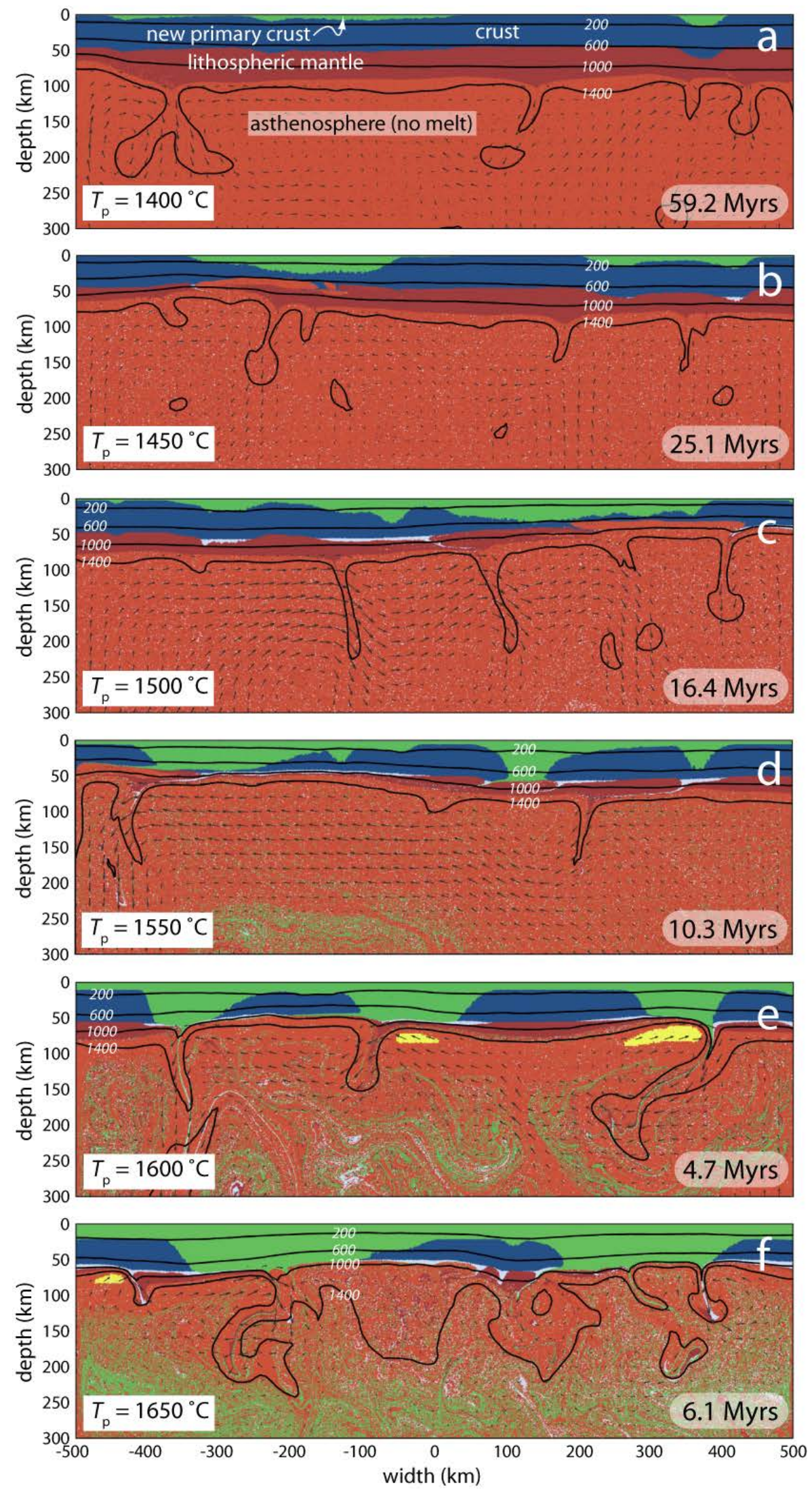

Figure S10. Snapshots from experiments with $45 \mathrm{~km}$ thick initial primary crust and wet mantle rheology. a, $T_{p}$ $=1400{ }^{\circ} \mathrm{C} ; \mathbf{b}, T_{p}=1450{ }^{\circ} \mathrm{C} ; \mathbf{c}, T_{p}=1500{ }^{\circ} \mathrm{C} ; \mathbf{d}, T_{p}=1550{ }^{\circ} \mathrm{C} ; \mathbf{e}, T_{p}=1600{ }^{\circ} \mathrm{C}$; and, f, $T_{p}=1650{ }^{\circ} \mathrm{C}$. Colours: dark blue, initial primary crust; light blue, negatively buoyant initial primary crust; dark pink-brown, lithospheric mantle; light pink-brown, unmelted asthenosphere; and yellow, melt-bearing asthenosphere). 

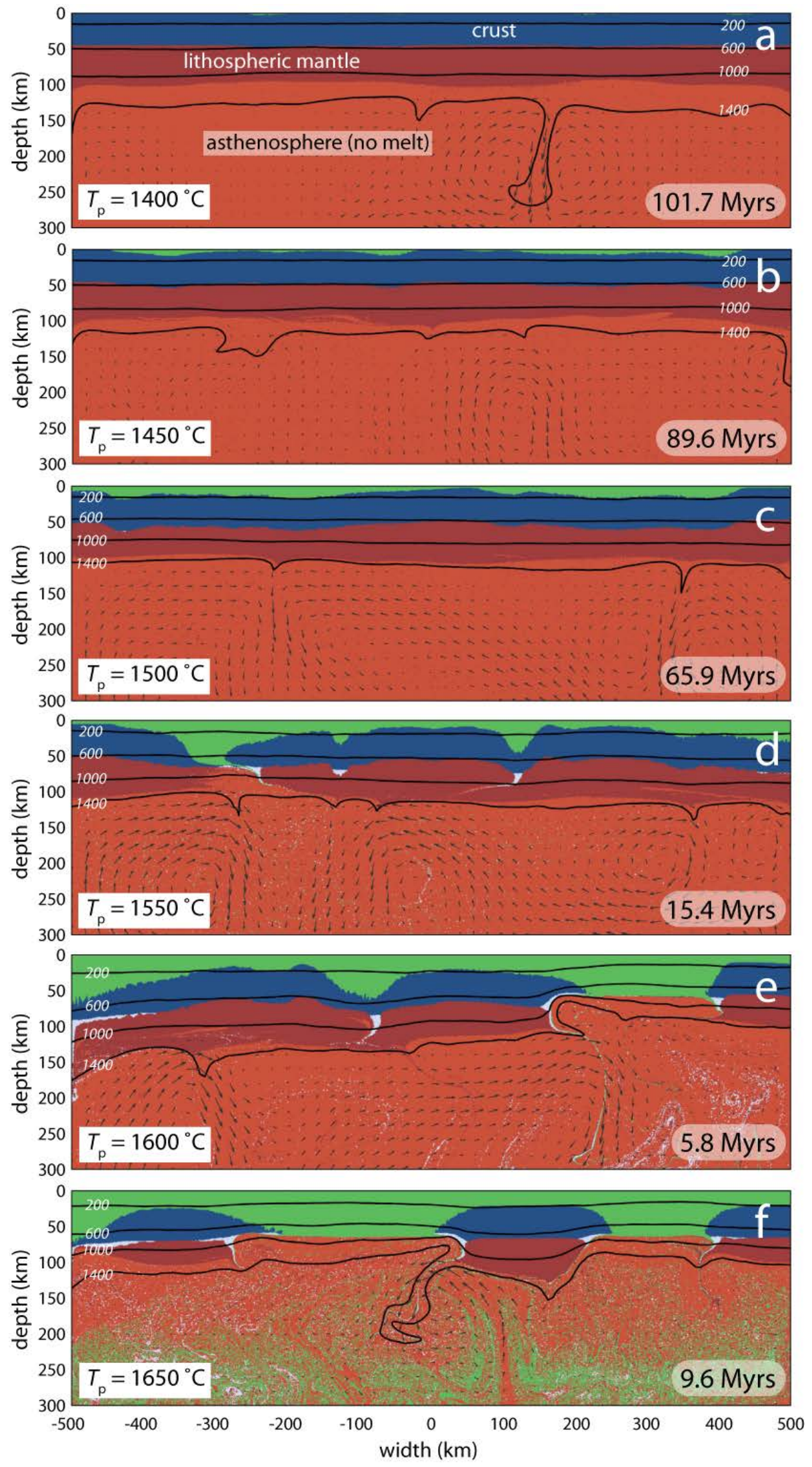

Figure S11. Snapshots from experiments with $45 \mathrm{~km}$ thick initial primary crust and dry mantle rheology. a, $T_{p}=$ $1400{ }^{\circ} \mathrm{C} ; \mathbf{b}, T_{p}=1450{ }^{\circ} \mathrm{C} ; \mathbf{c}, T_{p}=1500{ }^{\circ} \mathrm{C} ; \mathbf{d}, T_{p}=1550{ }^{\circ} \mathrm{C} ; \mathbf{e}, T_{p}=1600{ }^{\circ} \mathrm{C}$; and, f, $T_{p}=1650{ }^{\circ} \mathrm{C}$. Colours: dark blue, initial primary crust; light blue, negatively buoyant initial primary crust; dark pink-brown, lithospheric mantle; light pink-brown, unmelted asthenosphere; and yellow, melt-bearing asthenosphere). 

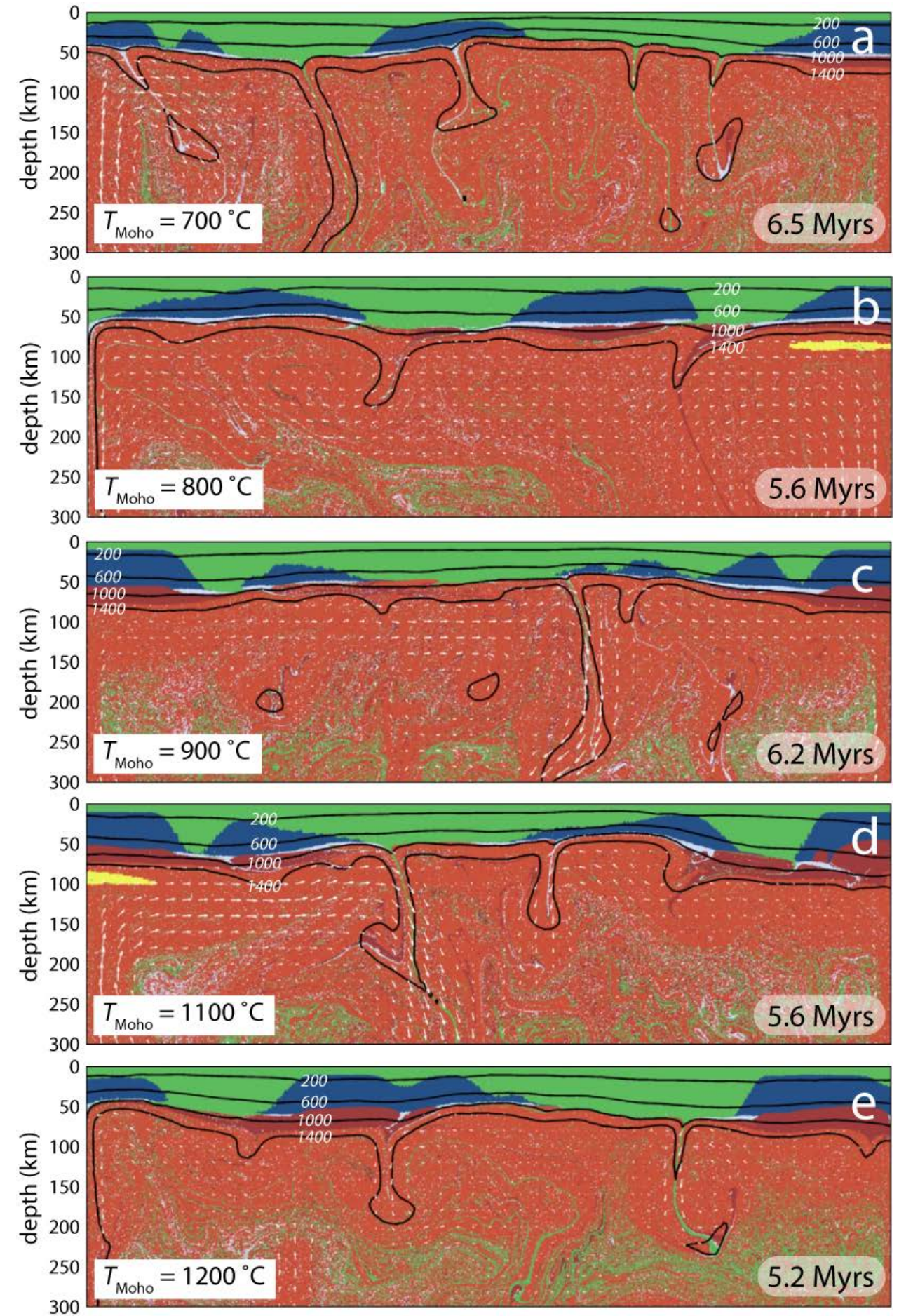

Figure S12. Snapshots from experiments with $45 \mathrm{~km}$ thick initial primary crust and wet mantle rheology. a, $T_{\text {Moho }}=700{ }^{\circ} \mathrm{C} ; \mathbf{b}, T_{\text {Moho }}=800{ }^{\circ} \mathrm{C} ; \mathbf{c}, T_{\text {Moho }}=900{ }^{\circ} \mathrm{C} ; \mathbf{d}, T_{\text {Moho }}=1100{ }^{\circ} \mathrm{C}$; and, $\mathbf{e}, T_{\text {Moho }}=1200{ }^{\circ} \mathrm{C}$. Colours: dark blue, initial primary crust; light blue, negatively buoyant initial primary crust; dark pink-brown, lithospheric mantle; light pink-brown, unmelted asthenosphere; and yellow, melt-bearing asthenosphere). 


\subsubsection{Physics of dripping instabilities}

All simulations described above are performed with a hydrous crust, which is a worstcase scenario as the crust becomes negatively buoyant only once it is thickened sufficiently (as described in the main text). We have performed additional simulations with an anhydrous crust, in which almost the full crustal thickness is negatively buoyant. However, since the anhydrous crust is relatively cold, the effective viscosity is too high to allow formation of rapid crustal-scale dripping instabilities. Instead, the experiments behave in a fairly similar manner to those described above in which only parts of the base of the crust drip off, generally above or in the vicinity of upwelling partially molten zones in the mantle.

Insight into the basic physics of the dripping instability is obtained using dimensional analysis. Assuming a layer at the base of the crust with thickness $H$, it will approximately affect a region of width $H$ and sink with the Stokes sinking velocity, given by

$$
V_{z} \propto \frac{C \Delta \rho g H^{2}}{\eta}
$$

where $C$ is a correction factor, $\Delta \rho$ the average density difference between the crust and the underlying mantle, and $\eta$ the effective viscosity immediately above or below the Moho.

The characteristic velocity of isotherms due to diffusion is given by

$$
V_{\text {diff }} \propto \frac{\kappa}{H}
$$

For a dripping instability to occur, lateral variations in density should exist, which implies that the instability must grow faster than the characteristic diffusion time (so $t_{a d v}>t_{d}$ ) otherwise the geotherm at the Moho would be equalized. This results in a non-dimensional critical buoyancy Rayleigh number, given by

$$
R_{b}=\frac{V_{z}}{V_{\text {diff }}}=\frac{C \Delta \rho g H^{3}}{\eta \kappa}
$$

which should be larger than 1 for a dripping instability to occur. Some parameters in this equation are well constrained (namely $\kappa=10^{-6} \mathrm{~m}^{2} / \mathrm{s}, \mathrm{g}=10 \mathrm{~m} / \mathrm{s}^{2}, \Delta \rho \sim 50-200 \mathrm{~kg} / \mathrm{m}^{3}$ ), whereas others, such as viscosity and layer thickness, are more poorly defined, and $\mathrm{C}$ is likely to be a constant based on earlier work (Conrad \& Molnar, 1997; Thielmann \& Kaus, 2012).

Analysing the numerical experiments at the stage where the dripping instabilities start to form provides a test of the validity of this simple approximation. This task has been undertaken for a number of the experiments in which vertical profiles at the location where a dripping instability occurs were analysed by computing the local thickness and average density difference of the negatively buoyant layer, and determining the maximum viscosity in this region, which generally occurs within the mantle lithosphere. The results of this analysis are summarized in Table S2. 


\begin{tabular}{|c|c|c|c|c|c|c|c|}
\hline \multirow[t]{2}{*}{ Simulation name } & Time & $\mathrm{x}[\mathrm{km}]$ & Av. $\quad \Delta \rho$ & Max $\eta$ [Pas] & $\mathrm{H}[\mathrm{km}]$ & $\mathrm{T}_{\text {moho }}[\mathrm{C}]$ & $\Delta \rho \mathrm{gH}^{3} /(\eta \kappa)$ \\
\hline & \multicolumn{2}{|l|}{ [Myrs] } & \multicolumn{5}{|l|}{$\left[\mathrm{kg} / \mathrm{m}^{3}\right]$} \\
\hline$T_{p} 1600$, Crust $45 \mathrm{~km}$, Wet & 1.92 & -83 & 79 & $5.2 \times 10^{19}$ & 10 & 996 & 15.0 \\
\hline$T_{p} 1600$, Crust $45 \mathrm{~km}$, Wet & 1.92 & 378 & 67 & $4.9 \times 10^{19}$ & 10 & 986 & 13.6 \\
\hline$T_{p} 1600$, Crust $45 \mathrm{~km}$, Wet & 1.97 & -320 & 85 & $2.5 \times 10^{19}$ & 11 & 1014 & 45.6 \\
\hline$T_{p} 1600$, Crust $45 \mathrm{~km}$, Wet & 2.22 & -22 & 185 & $1.3 \times 10^{18}$ & 14 & 1064 & 3409 \\
\hline$T_{p} 1600$, Crust $45 \mathrm{~km}$, Wet & 2.20 & 350 & 109 & $1.0 \times 10^{18}$ & 10 & 1097 & 1094 \\
\hline$T_{p} 1650$, Crust $45 \mathrm{~km}$, Wet & 2.61 & 112 & 69 & $3.5 \times 10^{19}$ & 13 & 994 & 42.3 \\
\hline$T_{p} 1650$, Crust $45 \mathrm{~km}$, Wet & 2.56 & 352 & 94 & $3.0 \times 10^{19}$ & 9 & 964 & 23.2 \\
\hline$T_{p} 1650$, Crust $45 \mathrm{~km}$, Wet & 2.56 & -127 & 108 & $1.9 \times 10^{19}$ & 10 & 977 & 56.4 \\
\hline$T_{p} 1500$, Crust $45 \mathrm{~km}$, Wet & 3.23 & -52 & 62 & $8.9 \times 10^{18}$ & 11 & 1041 & 93.1 \\
\hline$T_{p} 1550$, Crust $45 \mathrm{~km}$, Wet & 1.67 & -128 & 61 & $4.0 \times 10^{19}$ & 13 & 1033 & 33.23 \\
\hline$T_{p} 1550$, Crust $45 \mathrm{~km}$, Wet & 1.59 & 122 & 85 & $9.9 \times 10^{18}$ & 13 & 1036 & 189 \\
\hline$T_{p} 1550$, Crust $45 \mathrm{~km}$, Wet & 1.59 & 369 & 73 & $1.4 \times 10^{19}$ & 15 & 1061 & 175 \\
\hline$T_{p} 1550$, Crust $45 \mathrm{~km}$, Wet & 1.63 & -318 & 82 & $9.5 \times 10^{18}$ & 15 & 1078 & 290 \\
\hline$T_{p} 1650$, Crust $45 \mathrm{~km}$, Dry & 4.32 & -127 & 139 & $1.4 \times 10^{19}$ & 15 & 1039 & 336 \\
\hline$T_{p} 1650$, Crust 45 km, Dry & 4.33 & 355 & 127 & $5.3 \times 10^{19}$ & 15 & 1031 & 81 \\
\hline$T_{p} 1650$, Crust 45 km, Dry & 4.47 & 330 & 152 & $3.0 \times 10^{18}$ & 20 & 1162 & 4056 \\
\hline$T_{p} 1650$, Crust 45 km, Dry & 4.48 & -80 & 172 & $2.6 \times 10^{18}$ & 20 & 1173 & 5231 \\
\hline$T_{p} 1650$, Crust $45 \mathrm{~km}$, Dry & 4.69 & 300 & 130 & $1.9 \times 10^{19}$ & 25 & 1096 & 986 \\
\hline$T_{p} 1600$, Crust 45 km, Dry & 3.32 & -80 & 121 & $2.5 \times 10^{20}$ & 13 & 1027 & 11 \\
\hline$T_{p} 1600$, Crust $45 \mathrm{~km}$, Dry & 3.46 & 379 & 125 & $8.6 \times 10^{19}$ & 15 & 1046 & 49 \\
\hline$T_{p} 1600$, Crust 45 km, Dry & 3.78 & 270 & 148 & $1.1 \times 10^{20}$ & 17 & 1027 & 64 \\
\hline$T_{p} 1550$, Crust 45 km, Dry & 3.53 & -310 & 31 & $5.7 \times 10^{19}$ & 14 & 1049 & 15 \\
\hline$T_{p} 1550$, Crust 45 km, Dry & 3.53 & 122 & 126 & $5.1 \times 10^{19}$ & 15 & 1095 & 83 \\
\hline$T_{p} 1600$, Crust $25 \mathrm{~km}$, Dry & 5.20 & -68 & 165 & $1.4 \times 10^{19}$ & 17 & 1147 & 566 \\
\hline$T_{p} 1600$, Crust $25 \mathrm{~km}$, Wet & 3.01 & 260 & 132 & $2.5 \times 10^{18}$ & 12 & 1094 & 927 \\
\hline$T_{p} 1600$, Crust $25 \mathrm{~km}$, Wet & 3.12 & -190 & 89 & $1.3 \times 10^{19}$ & 7 & 978 & 23 \\
\hline
\end{tabular}

Table S2. Measured parameters at the onset of a dripping instability from the numerical simulations. Black colors indicate the first dripping instabilities that occur in the model. Red colors indicate drips that form at a later stage. In most cases these instabilities form over significant upwellings.

The results indicate that the onset of the first instabilities is well captured with the expression for $R_{b}$ given above, provided that a value for $\mathrm{C}$ of 0.1 is used, after which drips are predicted to develop as soon as $R_{b}>1$. Later instabilities commonly form above the larger partially molten upwellings. In this case, the velocity of the drips has to be not only faster than diffusion but also faster than the upward motion of the isentropically melting mantle. As a result, the condition $R_{b}>1$ is insufficient and $R_{b}>100$ is typically required.

The simple scaling law may be used to obtain insight into the maximum viscosity and minimum layer thicknesses that are required for a drip to develop at the Moho. Solving for $\mathrm{H}$ gives 


$$
H=\left(\frac{R_{b, c r i t} \kappa \eta}{C \Delta \rho g}\right)^{\frac{1}{3}}
$$

where $R_{b, c r i t}$ is the critical number (between 1 and 100 for most of the experiments), $\mathrm{C}=0.1$, and all other parameters as described above. Figure S13 shows a comparison of the analytical predictions with the numerical results at the onset of dripping. The agreement is reasonable and shows that a hot mantle lithosphere, which has smaller effective viscosities, will develop smaller drips. As the surface/volume ratio of smaller drips is larger, we expect them to heat in an efficient manner and therefore potentially melt (cf. Elkins-Tanton, 2005).

Our results indicate that layers thinner than $5 \mathrm{~km}$ would need a very low viscosity to become negatively buoyant and drip-off, or, alternatively, they would need to be thickened by another process (for example, by an adjacent hot upwelling). Yet, once a drip starts going, our simplified analysis strongly underestimates the velocity of the drips, and numerical simulations show that the resulting drips take most of the negatively buoyant crustal material with them into the mantle. This is the reason that nearly all of the negatively buoyant crust disappears. The stable crust does not disappear into the mantle (there is almost no "dark blue" material present in the mantle in the snapshots from the experiments), which further supports our interpretation that the lower crust is indeed removed by RT instabilities. Both positive and negatively buoyant "new" crust is coloured green; the negatively buoyant crust sinks into the mantle through the same mechanism where it is likely to melt as discussed in the main text.

The effect of phase transitions on dynamics of the early Earth has been discussed before. Particularly, Davies (1992) conjectured that the basalt-eclogite transition could play a role by adding negative buoyancy to a plate with a thick crust and thereby add to the negative buoyancy of those plates. Yet, he concluded that:

"It is quite possible that the effect of the basalt-eclogite transformation could have increased the rate of plate tectonics, but perhaps not dramatically and only intermittently" (Davies, 1992).

Our models show that the phase transitions indeed play a major role in the early Earth. Yet, rather than extending the plate-tectonics regime by adding additional negative buoyancy, the phase transitions help to drive rapid crustal recycling of an Earth that was otherwise in the drip tectonics mode. The exact physics of why the Earth switched from a drip-tectonics to a plate-tectonics regime remains to be understood, but our models do suggest that petrological constraints should be taken into account in such models. 


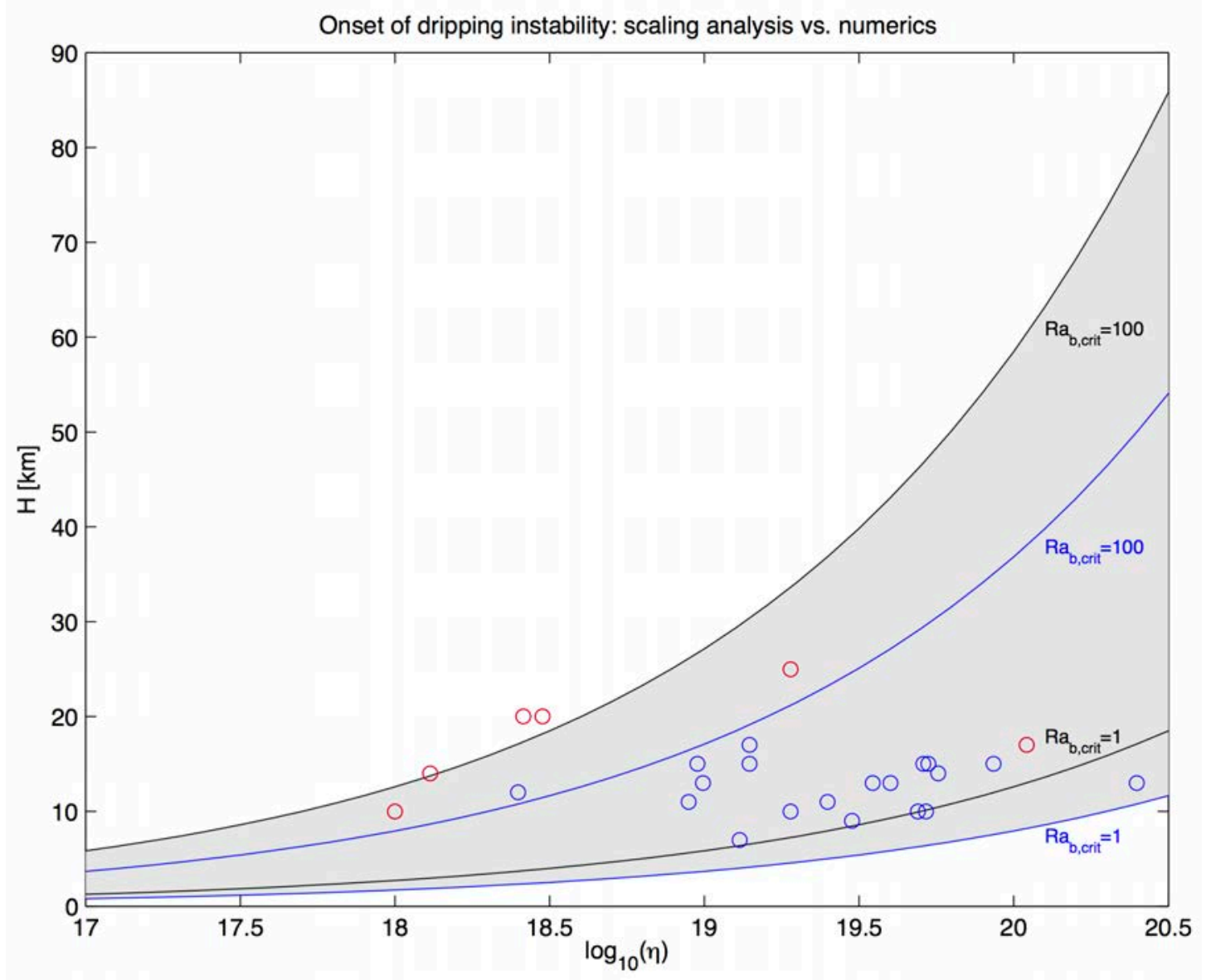

Figure S13: Analytical predictions for the minimum negatively buoyant layer thickness as a function of viscosity that is required for a dripping instability to develop (for this $R a_{b}>1$ ). Solid lines are predictions assuming $\Delta \rho=50$ (black lines) and $\Delta \rho=200 \mathrm{~kg} / \mathrm{m}^{3}$ (blue lines). Circles are the results from the numerical simulations, where blue indicate the first drips that form in the simulations and red circles indicate drips that form at a later stage (typically above large scale upwellings). The agreement is quite reasonable given the simplicity of the scaling analysis, and shows that only small drips will form in a hotter mantle (which has a lower viscosity). 


\section{References}

Ahmad, T., Dragusanu, C. \& Tanaka, T. Provenance of Proterozoic Basal Aravalli mafic volcanic rocks from Rajasthan, Northwestern India: $\mathrm{Nd}$ isotopes evidence for enriched mantle reservoirs. Precambrian Res. 162, 150-159 (2008).

Balakrishnan, S., Rajamani, V., Hanson, G. N. U-Pb ages for zircon and titanite from the Ramagiri area, southern India: Evidence for accretionary origin of the eastern Dharwar craton during the late Archean. J. Geology 107, 69-86 (1999).

Berry, A. J., Danyushevsky, L. V., O’Neill, H. St C., Newville, M. \& Sutton, S. R. Oxidation state of iron in komatiitic melt inclusions indicates hot Archaean mantle. Nature 455, 960963 (2008).

Bittner, D. \& Schmeling, H. Numerical modelling of melting processes and induced diapirism in the lower crust. Geophys. J. Int. 123, 59-70 (1995).

Brown, M. Metamorphic conditions in orogenic belts: A record of secular change. Int. Geol. Rev. 49, 193-234 (2007).

Card, K. D. A review of the Superior province of the Canadian shield, a product of Archean accretion. Precambrian Res. 48, 99-156 (1990).

Carter, N. L. \& Tsenn, M. C. Flow properties of continental lithosphere. Tectonophys. 136, 27-63 (1987).

Connolly, J. A. D. Computation of phase equilibria by linear programming: a tool for geodynamic modeling and its application to subduction zone decarbonation. Earth Planet. Sci. Lett. 236, 524-541 (2005).

Conrad, C. \& Molnar, P. The growth of Rayleigh-Taylor-type instabilities in the lithosphere for various rheological and density structures. Geophys. J. Int. 129, 95-112 (1997).

Crameri, F. \& Kaus, B. Parameters that control lithospheric-scale thermal localization on terrestrial planets. Geophys. Res. Lett. 37, Article Number: L09308 (2010).

Crameri, F. et al. A comparison of numerical surface topography calculations in geodynamic modelling: an evaluation of the 'sticky air' method. Geophys. J. Int. 189, 38-54 (2012).

Dabrowski, M., Krotkiewski, M. \& Schmid, D. W. MILAMIN: MATLAB-based finite element method solver for large problems. Geochemistry, Geophysics, Geosystems 9, Article Number: Q04030 (2008).

Davies, G. On the Emergence of Plate-Tectonics. Geology 20, 963-966 (1992).

Deubelbeiss, Y., Kaus, B. \& Connolly, J. A. D. Direct numerical simulation of two-phase flow: Effective rheology and flow patterns of particle suspensions. Earth Planet. Sci. Lett. 290, 1-12 (2010). 
Diener, J. F. A. \& Powell, R. Revised activity-composition relations for clinopyroxene and amphibole. J. Metamorph. Geol. 30, 131-142 (2012).

Elkins-Tanton, L. T. Continental magmatism caused by lithospheric delimination. In Foulger, G. R., Natland, J. H., Presnall, D. C. \& Anderson, D. L. (eds) Plates, Plumes, and Paradigms, Geological Society of America Special Paper 388, 449-461 (2005).

Gerya, T. V. \& Yuen, D. A. Robust characteristics method for modelling multiphase viscoelasto-plastic thermo-mechanical problems. Phys. Earth Planet. Int. 163, 83-105 (2007).

Ghiorso, Mark S., Hirschmann, Marc M., Reiners, Peter W., \& Kress, Victor C. III The pMELTS: An revision of MELTS aimed at improving calculation of phase relations and major element partitioning involved in partial melting of the mantle at pressures up to $3 \mathrm{GPa}$. Geochemistry, Geophysics, Geosystems 3, Article Number: 1030 (2002).

Green, M. G., Sylvester, P. J. \& Buick, R. Growth and recycling of early Archaean continental crust: geochemical evidence from the Coonterunah and Warrawoona Groups, Pilbara Craton, Australia. Tectonophys. 322, 69-88 (2000).

Herzberg, C., Condie, K. \& Korenaga, J. Thermal history of the Earth and its petrological expression. Earth Planet. Sci. Lett. 292, 79-88 (2010).

Hirth, G. \& Kohlstedt, D. Rheology of the upper mantle and the mantle wedge: A view from the experimentalists. In J. Eiler (ed) Inside the Subduction Factory, Geophysical Monograph American Geophysical Union, Washington, D.C. 138, 83-105 (2003).

Holland T. J. B. \& Powell R. An internally consistent thermodynamic data set for phases of petrological interest. J. Metamorph. Geol. 16, 309-43 (1998).

Holland, T. J. B. \& Powell. R. Activity-composition relations for phases in petrological calculations: an asymmetric multicomponent formulation. Contrib. Mineral. Petrol. 145, 492-501 (2003).

Kato, Y. \& Nakamura, K. Origin and global tectonic significance of Early Archean cherts from the Marble Bar greenstone belt, Pilbara Craton, Western Australia. Precambrian Res. 125, 191-243 (2003).

Katz, R. F., Spiegelman, M. \& Langmuir, C. H. A new parameterization of hydrous mantle melting. Geochemistry, Geophysics, Geosystems 4, Article Number: 1073 (2003).

Kaus, B. Factors that control the angle of shear bands in geodynamic numerical models of brittle deformation. Tectonophys. 484, 36-47 (2010).

May, D. A. \& Moresi, L. Preconditioned iterative methods for Stokes flow problems arising in computational geodynamics. Phys. Earth Planet. Int. 171, 33-47 (2008).

Polat, A. et al. The origin and compositions of Mesoarchean oceanic crust: Evidence from the 3075 Ma Ivisaartoq greenstone belt, SW Greenland. Lithos 100, 293-321 (2008). 
Schmeling, H. et al. A benchmark comparison of spontaneous subduction models--Towards a free surface. Phys. Earth Planet. Int. 171, 198-223 (2008).

Shchipansky, A. A. et al. 2.8 Ga boninite-hosting partial suprasubduction zone ophiolite sequences from the north Karelian greenstone belt, NE Baltic shield, Russia. In Kusky, T.M., ed., Precambrian ophiolites and related rocks. Elsevier B.V., Developments in Precambrian geology 13, 425-486 (2004).

Sizova, E., Gerya, T., Brown, M. \& Perchuk, L. Subduction styles in the Precambrian: Insight from numerical experiments. Lithos 116, 209-229 (2010).

Smithies, R. H., Van Kranendonk, M. J. \& Champion, D. C. It started with a plume - early Archaean basaltic proto-continental crust. Earth Planet. Sci. Lett. 238, 284-297 (2005).

St-Onge, M. R., Lucas, S. B., Scott, D. J. \& Wodicka, N. Upper and lower plate juxtaposition, deformation and metamorphism during crustal convergence, Trans-Hudson Orogen (QuebecBaffin segment), Canada. Precambrian Res. 93, 27-49 (1999).

Tackley, P. J. \& King, S. D. Testing the tracer ratio method for modeling active compositional fields in mantle convection simulations. Geochemistry, Geophysics, Geosystems 4, Article Number: 8302 (2003).

Thielmann, M. \& Kaus, B. Shear heating induced lithospheric-scale localization: Does it result in subduction? Earth Planet. Sci. Lett. 359-360, 1-13 (2012).

Volpe, A. M. \& Macdougall, J. D. Geochemistry and isotopic characteristics of mafic (Phulad ophiolite) and related rocks in the Delhi-Supergroup, Rajasthan, India - implications for rifting in the Proterozoic. Precambrian Res. 48, 167-191 (1990).

Wang, X. C., Li, X. H., Li, W. X. \& Li, Z. X. Ca. 825 Ma komatiitic basalts in South China: First evidence for $>1500^{\circ} \mathrm{C}$ mantle melts by a Rodinian mantle plume. Geology 35, 11031106 (2007).

White, R. W., Powell, R. \& Clarke, G. L. The interpretation of reaction textures in Fe-rich metapelitic granulites of the Musgrave Block, central Australia: Constraints from mineral equilibria calculations in the system $\mathrm{K}_{2} \mathrm{O}-\mathrm{FeO}-\mathrm{MgO}-\mathrm{Al}_{2} \mathrm{O}_{3}-\mathrm{SiO}_{2}-\mathrm{H}_{2} \mathrm{O}-\mathrm{TiO}_{2}-\mathrm{Fe}_{2} \mathrm{O}_{3} . J$. Metamorph. Geol. 20, 41-55 (2002).

White, R. W., Powell, R. \& Holland T. J. B. Progress relating to calculation of partial melting equilibria for metapelites. J. Metamorph. Geol. 25, 511-527 (2007).

White, R. W., Powell, R., Holland, T. J. B. \& Worley, B. The effect of $\mathrm{TiO}_{2}$ and $\mathrm{Fe}_{2} \mathrm{O}_{3}$ on metapelitic assemblages at greenschist and amphibolite facies conditions: mineral equilibria calculations in the system $\mathrm{K}_{2} \mathrm{O}-\mathrm{FeO}-\mathrm{MgO}-\mathrm{Al}_{2} \mathrm{O}_{3}-\mathrm{SiO}_{2}-\mathrm{H}_{2} \mathrm{O}-\mathrm{TiO}_{2}-\mathrm{Fe}_{2} \mathrm{O}_{3}$. J. Metamorph. Geol. 18, 497-511 (2000).

Yamato, P., Kaus, B., Mouthereau, F. \& Castelltort, S. Dynamic constraints on the crustalscale rheology of the Zagros fold belt, Iran. Geology 39, 815-818 (2011). 